\title{
An Insight into microRNA156 Role in Salinity Stress Responses of Alfalfa
}

\author{
Muhammad Arshad ${ }^{1}$, Margaret Y. Gruber ${ }^{2}$, Ken Wall ${ }^{3}$ and Abdelali Hannoufa ${ }^{1 *}$ \\ ${ }^{1}$ Agriculture and Agri-Food Canada, London, ON, Canada, ${ }^{2}$ Agriculture and Agri-Food Canada, Saskatoon, SK, Canada, \\ ${ }^{3}$ Agriculture and Agri-Food Canada, Swift Current, SK, Canada
}

\section{OPEN ACCESS}

Edited by:

Vicent Arbona,

Jaume I University, Spain

Reviewed by:

László Szabados,

MTA Biological Research Center,

Hungary

Juan Chen,

Northwest A\&F University, China

*Correspondence:

Abdelali Hannoufa

abdelali.hannoufa@agr.gc.ca

Specialty section:

This article was submitted to

Plant Abiotic Stress,

a section of the journal

Frontiers in Plant Science

Received: 23 November 2016

Accepted: 01 March 2017

Published: 14 March 2017

Citation:

Arshad M, Gruber MY, Wall K and Hannoufa A (2017) An Insight into microRNA156 Role in Salinity Stress

Responses of Alfalfa.

Front. Plant Sci. 8:356.

doi: 10.3389/fpls.2017.00356
Salinity is one of the major abiotic stresses affecting alfalfa productivity. Developing salinity tolerant alfalfa genotypes could contribute to sustainable crop production. The functions of microRNA156 (miR156) have been investigated in several plant species, but so far, no studies have been published that explore the role of miR156 in alfalfa response to salinity stress. In this work, we studied the role of miR156 in modulating commercially important traits of alfalfa under salinity stress. Our results revealed that overexpression of miR156 increased biomass, number of branches and time to complete growth stages, while it reduced plant height under control and salinity stress conditions. We observed a miR156-related reduction in neutral detergent fiber under non-stress, and acid detergent fiber under mild salinity stress conditions. In addition, enhanced total Kjeldahl nitrogen content was recorded in miR156 overexpressing genotypes under severe salinity stress. Furthermore, alfalfa genotypes overexpressing miR156 exhibited an altered ion homeostasis under salinity conditions. Under severe salinity stress, miR156 downregulated SPL transcription factor family genes, modified expression of other important transcription factors, and downstream salt stress responsive genes. Taken together, our results reveal that miR156 plays a role in mediating physiological and transcriptional responses of alfalfa to salinity stress.

Keywords: salt stress, miR156, alfalfa, biomass, ions

\section{INTRODUCTION}

Salinity is a major threat to crop productivity and yield. Presently, almost half of the world's irrigated land and about $20 \%$ of global cultivated land is affected by salinity (Paul and Lade, 2014). Ions such as $\mathrm{Na}^{+}$present in the outside media enter into root cells establishing a large electrochemical gradient, which promotes passive influx of salt ions through channels and transporters located on the plasma membrane (Sun et al., 2009). This $\mathrm{Na}^{+}$influx raises sodium concentration inside the cytosol triggering $\mathrm{K}^{+}$efflux, which disturbs the $\mathrm{K}^{+} / \mathrm{Na}^{+}$ratio and thereby intensifies salt stress conditions (Sun et al., 2009; Britto et al., 2010). Salinity also exerts osmotic and ionic stress in plants, which decreases plant root growth and leaf expansion. In the long term, $\mathrm{Na}^{+}$ and $\mathrm{Cl}^{-}$accumulate in cells to toxic levels causing intrinsic injury leading to premature chlorosis or death of leaves (Munns, 2002).

Legume crops play a distinct role in ecological and agricultural aspects due to their ability to interact symbiotically with soil microorganisms to form nodules and fix atmospheric nitrogen (Wezel et al., 2014). Alfalfa (Medicago sativa) is an important legume crop that is not only used as forage for animal consumption but also to enhance soil fertility (Graham and Vance, 2003). Alfalfa cultivars carry large genetic diversity ranging from susceptible to tolerant to moderate salinity, but 
severe salt stress drastically reduces growth and productivity of alfalfa (Munns and Tester, 2008; Tuoxiong et al., 2010; Long et al., 2012; Steppuhn et al., 2012; Wang B.-P. et al., 2013). Salinity negatively affects plant growth, biomass production, forage quality, and nitrogen and antioxidant levels in plants (Parvaiz and Satyawati, 2008; Wang et al., 2009; Li et al., 2010).

MicroRNAs (miRNAs) are sequence-specific regulators of post transcriptional gene expression in eukaryotes. As nonprotein coding genes, miRNAs are predominantly transcribed by RNA polymerase II, which requires Mediator with a conserved multi-subunit complex and the RNA splicing mechanism (Kim et al., 2011; Bielewicz et al., 2013). The transcription of miRNA genes results in production of a primary miRNA transcript containing a stem loop structure, which is further processed into an active mature miRNA in two steps. First, RNase III endoribonuclease removes the stem loop - the miRNA precursor from the primary miRNA transcript. Secondly, this miRNA precursor matures by forming a $-5 \mathrm{p} /-3 \mathrm{p}$ miRNA duplex with two nucleotide $3^{\prime}$ overhangs. The mature miRNA targets genes by interacting with a complex containing an ARGONAUTE protein (Couzigou and Combier, 2016). In plants, miRNA regulates gene expression mainly by transcript cleavage or translational inhibition (Brodersen et al., 2008; Rogers and Chen, 2013; Reis et al., 2015). The miRNAs detect their targets by binding to (1) miRNA complementary sequences known as miRNA responsive elements, (2) 5' untranslated regions or (3), 3' untranslated regions (Rhoades et al., 2002; Jones-Rhoades and Bartel, 2004; Allen et al., 2005). Although plant miRNAs affect a range of genes that encode proteins with several functions, transcription factors remain their main targets (Hobert, 2004, 2008).

Plant microRNAs affect a variety of plant physiological traits such as root growth, apical dominance, plant biomass, flowering time, fruit and seed development, and environmental stress responses (Zhang and Wang, 2015). A study by (Wang M. et al., 2013) showed altered expression of five microRNAs (miR156, miR162, miR159, miR395, and miR396) in response to salt stress in cotton. MicroRNA156 (miR156) is conserved across plants and its role has widely been investigated in a variety of crops, model plants and tree species (Aung et al., 2015b; Wang and Wang, 2015). MiR156 delays flowering and increase root development in alfalfa, enhances biomass accumulation in switchgrass and leaf number in tomato as well as improves heat stress memory and abiotic stress tolerance in Arabidopsis (Fu et al., 2012; Cui et al., 2014; Stief et al., 2014; Aung et al., 2015a; Wang et al., 2015).

SQUAMOSA PROMOTER BINDING PROTEIN-LIKE (SPL) is a family of transcription factors regulated by microRNA156, and SPLS further regulate expression of downstream genes involved in specific traits (Aung et al., 2015b). Biological processes regulated by SPLs in plants include phase change from vegetative to reproductive, secondary metabolites synthesis and stress responses. MiR156-mediated downregulation of three SPL genes (SPL2, SPL9, and SPL11) enhanced plant response to heat stress in Arabidopsis (Stief et al., 2014). Similarly, miR156/SPL module positively affected root growth and secondary metabolite accumulation, leading to improvement of stress tolerance in Arabidopsis (Cui et al., 2014).
Other transcription factors including zinc finger proteins (ZFPs), WRKY, Apetala 2/Ethylene Response Factors (AP2/ERF) and basic region/leucine zipper motif (bZIP) have been described as important modulators of plant response to environmental stress (Singh et al., 2002; Ciftci-Yilmaz and Mittler, 2008; Jiang and Deyholos, 2009; Pandey and Somssich, 2009; Rushton et al., 2010; Mizoi et al., 2012; Shi et al., 2014; Hu et al., 2016). Overexpression of alfalfa AP2/ERF family genes (MsERF8 and MsERF11) enhanced tolerance to salinity in tobacco and Arabidopsis (Chen et al., 2012a,b). Similarly, overexpression of Glycine soja ZFP and WRKY20 improved drought and salt tolerance in alfalfa (Tang et al., 2013, 2014). Several studies showed involvement of bZIP transcription factor family genes in leaf senescence and modulating responses to various abiotic stresses including salinity and drought (Lee et al., 2006, 2010; Zou et al., 2008). Overexpression of stress-induced alfalfa bZIP $(M s Z I P)$ resulted in increased proline accumulation, soluble sugar content, relative water content and soluble protein content under drought and salt conditions in tobacco, which subsequently led to enhanced drought and salt stress tolerance (Li et al., 2013).

Abiotic stresses such as drought, salinity, and cold, regulate the expression of thousands of genes in plants at the transcriptional and the post transcriptional levels but the underlying molecular mechanism of salt tolerance in plants remains elusive (Zhu, 2002; Munns and Tester, 2008). Salinity induces expression of numerous genes to facilitate adaptive and defense responses in plants. The transcriptomes of two salt-tolerant alfalfa breeding populations were much more able to maintain their non-saline transcript levels and diversity under high saline conditions compared with a salt-sensitive population (Gruber et al., 2016). In terms of individual genes, salt-induced glycine rich plant proteins (GRPs) are characterized by their high content and repetitive sequences of glycine residues (Mangeon et al., 2010). Many GRPs are associated with the vascular system that pinpoints their role in stress responses (Ringli et al., 2001). Overexpression of alfalfa GRP increases sensitivity to ABA and abiotic stress in Arabidopsis (Long et al., 2013). A cytokinin receptor homolog (MsHK1) isolated from alfalfa root nodule showed induced expression under salt stress, indicating a potential role in salinity response (Coba de la Pena et al., 2008). The ability of plants to compartmentalize salt ions into vacuoles is considered a critical step toward maintenance of ion homeostasis inside the cell (Parida and Das, 2005). A plant tonoplast $\mathrm{Na}^{+} / \mathrm{H}^{+}$ antiporter, $N H X$, facilitates this crucial compartmentalisation step, and salt stress was shown to upregulate $N H X$ expression in plants (Silva and Geros, 2009). AtNHX1 overexpression mediated potassium transport and affected salinity response in tomato (Leidi et al., 2010). Transgenic alfalfa overexpressing the wheat NHX2 exhibited improved salt tolerance (Zhang et al., 2015). Furthermore, overexpression of alfalfa Rare Cold Inducible 2 (RCI2) enhanced tolerance to salt stress in Arabidopsis (Long et al., 2015).

In this study, we examined the role of miR156 in alfalfa salinity stress response. Our objective was to investigate the effects of miR156 in modulating the physiological and molecular mechanisms known to play a role in salt stress tolerance and 
forage nutrition. To our knowledge, this is the first study reporting a positive role for miR156 in salinity response of alfalfa.

\section{MATERIALS AND METHODS}

\section{Experimental Design}

Plant growth experiments were conducted using hydroponic tanks with saline solutions at the Salt Laboratory of Agriculture and Agri-Food Canada in Swift Current, Saskatchewan as described in Steppuhn et al. (2012), but with the following variations. We tested transgenic alfalfa genotypes overexpressing microRNA156 (miR156OE) and plants transformed with an empty vector (EV) that were generated by Aung et al. (2015a). In addition to genotypes A8, A11, and A11a described in (Aung et al. (2015a), we also included an additional genotype (A4a) with relatively low miR156 expression in our study (Supplementary Figure 1A). MiR156OE and EV plants were grown starting from foam plugs of rooted cuttings in tanks that featured three cuttings per genotype and five genotypes (EV and 4 miR156OE) randomly distributed in each tank. The overall experimental design included four tanks for each of three electroconductivity (EC) salt levels (i.e., EC $1.4 \mathrm{dSm}^{-1}, 7.0 \mathrm{dSm}^{-1}$, and $14 \mathrm{dSm}^{-1}$ ). All 12 tanks were randomized for location in a greenhouse under an average of $16 \mathrm{~h}$ daylight and $20^{\circ} \mathrm{C}$ temperature conditions (Supplementary Figure 1B). EC $1.4 \mathrm{dSm}^{-1}, 7.0 \mathrm{dSm}^{-1}$, and $14 \mathrm{dSm}^{-1}$ were designated as control, mild and severe salinity stress, respectively.

\section{Physiological Data Collection}

Physiological data were collected from four experiments (i.e., four re-growth harvests of forage material collected prior to blooming). For the first harvest, data were collected after 70 days of plant transplantation whereas for subsequent second, third, and fourth harvests, data were collected 30-35 days after the preceding harvest. Plant height was measured from the rooted cutting plug to the tip of the longest shoot. For root sample (4th harvest) collections, tanks were flooded to facilitate soil loosening. Alfalfa developmental stages (stage 0; early vegetative, stage 1;mid-vegitative, stage 2; late vegetative, stage 3; early bud, stage 4 ; late bud, stage 5; early flower) were determined from four harvests by examining the stems as described in Information Bulletin 217 (Fick and Mueller, 1989).

Leaf and root samples for RNA extraction, antioxidant and ion analysis were collected from the fourth harvest. Leaf RNA samples were collected from the tip of two shoots with no flower buds, three plants per genotype from each tank. Leaf samples for antioxidants were collected from two healthy shoots including tiny buds. RNA and antioxidant samples were frozen immediately in liquid nitrogen. Plant samples were first weighed to determine fresh weight or biomass. Dry weight was obtained by incubating samples in a forage drum drier at $40^{\circ} \mathrm{C}$ for 1-2 weeks. Dried samples from the fourth harvest were then ground for ions and nutrition analysis. Twenty centimeter-long root samples (measuring from the longest tip) were collected for RNA extraction from three plants per genotype per tank. Samples were then frozen immediately in liquid nitrogen.

\section{Determining Fiber and Nitrogen Content}

To assess forage quality, we determined the fiber content in alfalfa leaf material collected from the fourth harvest. Neutral detergent fiber (NDF) levels were measured using an ANKOM200 fiber analyzer (Model 200; ANKOM; Fairport, NY, USA) according to the ANKOM Neutral Detergent Fiber in Feeds Filter Bag Technique (Ferreira and Mertens, 2007). For acid detergent fiber (ADF), we followed a protocol described in Goering and Van Soest (1970). For total Kjeldahl nitrogen (TKN) measurements, we used a $\mathrm{H}_{2} \mathrm{SO}_{4} / \mathrm{Se} / \mathrm{Na}_{2} \mathrm{SO}_{4}$ digestion method as described in Varley (1966), and analysis was performed following a published method (Noel and Hambleton, 1976).

\section{Ion Analysis}

Concentration of ions $\left(\mathrm{Na}^{+}, \mathrm{Ca}^{2+}, \mathrm{Mg}^{2+}\right.$, and $\left.\mathrm{Zn}^{2+}\right)$ was measured from leaves of 1-month-old plants from the fourth harvest using $\mathrm{HClO}_{4} / \mathrm{HNO}_{3}$ digestion method (Jones, 1991) in the ICP-OES (Inductively Coupled Plasma - Optical Emission Spectroscopy) on a Fisher Scientific iCAP6300 Duo machine by following manufacturer's instructions. Briefly, $1 \mathrm{~g}$ sample was taken into PTFE high pressure vessels, and $5 \mathrm{~mL}$ of concentrated nitric acid and $5 \mathrm{~mL}$ water were added for digestion in Milestone Ethos EZ microwave. The digest was diluted with ultra-pure water before running the samples along with blanks for each digestion cycle. For data analysis, the instrument was calibrated, and samples were analyzed. We performed method detection limit study by analyzing three digestion blanks and the average values were taken for detection limits.

\section{Antioxidant Measurements}

Total antioxidant levels were determined from 1-month-old leaf samples (100 mg) using an antioxidant assay kit (Sigma-Aldrich, Oakville ON, Canada; catalog number CS0790) following the manufacturer's instructions. Antioxidant reactions were performed in a 96-well plate by reading endpoint absorbance at $405 \mathrm{~nm}$ using a plate reader (BioTek, Synergy 2, Winooski, VT, USA). Concentration of antioxidants was calculated using a Trolox $^{\mathrm{TM}}$ standard curve (Supplementary Figure 2).

\section{Gene Expression Analysis}

Leaf and root samples were ground using mortar and pestle into fine powder and $100 \mathrm{mg}$ representative sample was used for RNA extraction using the PowerPlant RNA Isolation Kit (Mo Bio Laboratories Inc., San Diego, CA, USA). Extracted RNA was treated with TURBO DNase (Ambion, Austin, TX, USA). One microgram of total RNA was used for cDNA synthesize using an iScript cDNA synthesis kit (Bio-Rad Laboratories, Mississauga, ON, Canada). Gene amplification was performed in a C1000 Touch ${ }^{\mathrm{TM}}$ Thermocycler Real-Time PCR System (BioRad) using SsoFast SYBR Green Master Mix (Bio-Rad). QRTPCR conditions were 1 cycle at $95^{\circ} \mathrm{C}$ for $30 \mathrm{~s}$, then 40 cycles at $95^{\circ} \mathrm{C}$ for $5 \mathrm{~s}, 60^{\circ} \mathrm{C}$ for $15 \mathrm{~s}$, followed by melting curve $65-95^{\circ} \mathrm{C}$ with $5 \mathrm{~s} /$ step, $+0.5^{\circ} \mathrm{C} /$ cycle. QRT-PCR data was analyzed using a CFX-Manager (Bio-Rad) with a $2^{-\Delta C T}$ method (Schmittgen and Livak, 2008). Suitable reference genes (ACC1, Actin) were selected (Supplementary Figure 3 ) and primers for reference and 
target genes were designed from $M$. sativa sequences (Gao et al., 2016) and are listed in Supplementary Table 1.

\section{Statistical Analysis}

GraphPad Prism software was used to statistically analyze the data. The $t$-test or Analysis of Variance (ANOVA) were used to test the significance followed by Tukey's HSD test for multiple comparisons. Statistical analyses were conducted on a sample size of 3-12 and $P$-value $<0.05$.

\section{RESULTS}

\section{MiR156 Improves Biomass Accumulation in Alfalfa under Salinity Stress}

Transgenic alfalfa genotypes exhibited variable levels of miR156 expression with A4a and A8 showing low expression, A11a medium and A11 higher expression of miR156 (Supplementary Figure 1A). In our study, alfalfa genotypes overexpressing miR156 accumulated significantly higher shoot dry biomass at least in two miR156OE genotypes (A4a, A8) compared to EV under control (EC 1.4). Three miR156OE genotypes (A4a, A11, and A11a) showed enhanced shoot biomass under severe salt stress (EC 14), while no significant difference was observed under mild salt stress (Figure 1A). Similar to leaves, significantly enhanced root dry biomass was observed in A4a and A8 under control conditions compared to EV (Figure 1B). Medium and high miR156 over-expressers (A11a, A11) exhibited significantly higher accumulation of dry root biomass compared to EV under severe stress conditions (Figure 1B). Furthermore, we observed an increased (statistically or/and numerically) fresh shoot and root biomass accumulation in miR156OE genotypes (except in A8 during severe stress) under control, mild and severe stress conditions (Supplementary Figure 4). We also compared shoot and root biomass gain in $\mathrm{EV}$ and miR156OE genotypes during mild and severe stress relative to their corresponding control plants, and results indicated that medium and high miR156 over-expressers (A11, A11a) consistently accumulated biomass that was significantly higher than EV. Low miR156 over-expressers, however, showed insignificant results with EV (Supplementary Figure 5). These results suggest that miR156 improves fresh and dry biomass in alfalfa under control and salinity stress conditions.

\section{MicroRNA156 Positively Regulates Physiological Responses of Alfalfa under Salinity Stress}

Plant physiological responses to salinity stress vary and depend on underlying molecular mechanisms (Ahmed et al., 2013). In our study, we measured plant height, number of stems or branches and plant developmental stages in EV and miR156OE genotypes under control, mild and severe salt stress conditions. Results revealed that under control conditions, low miR156 over-expressing plants were either significantly taller (A4a) or showed a similar height compared with EV (A8), while medium and high miR156 over-expressers (A11 and A11a) were

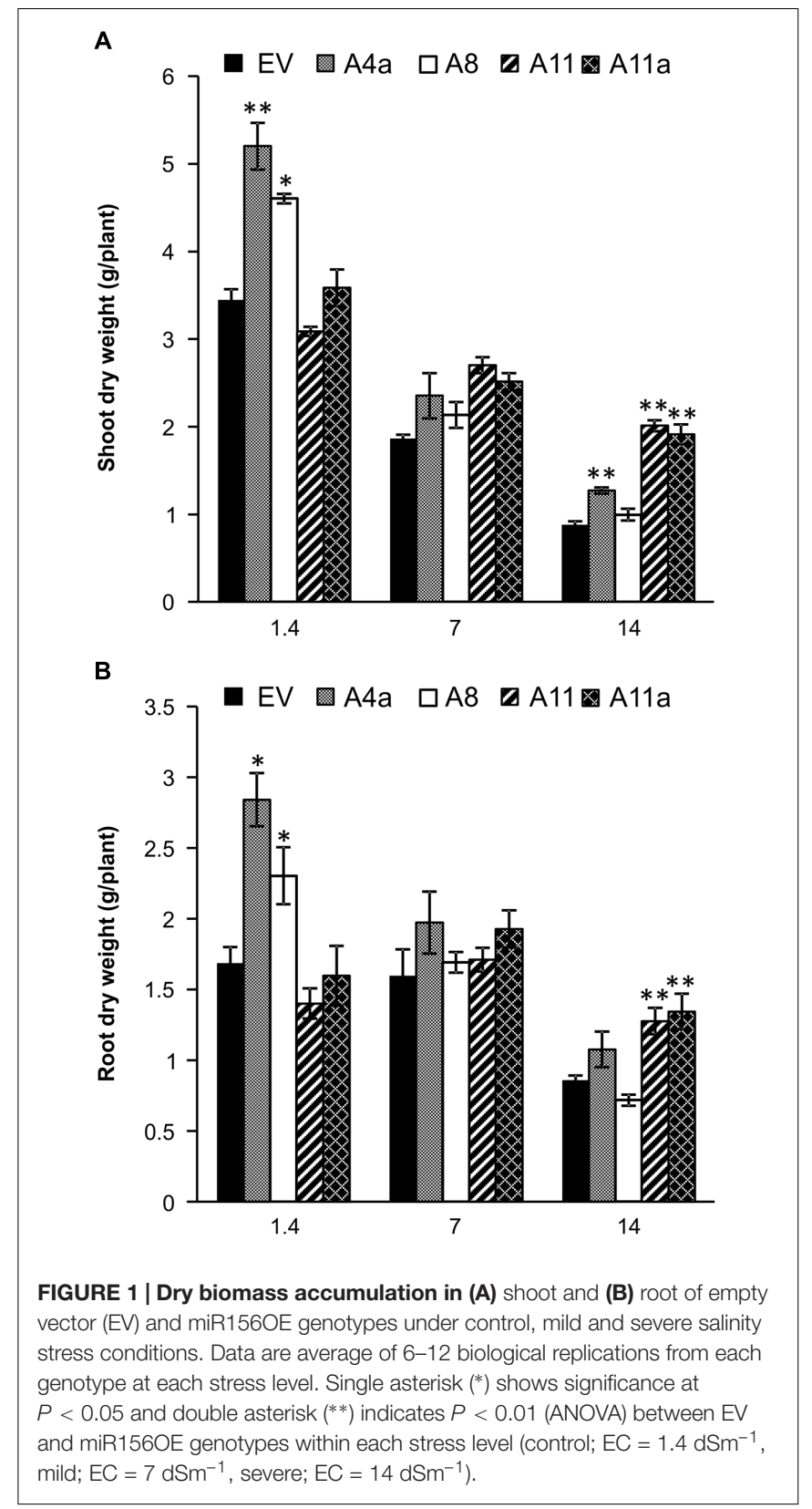

significantly shorter. A similar trend was observed in these genotypes under mild stress conditions (Figure 2A). Under severe stress, we recorded the same plant height for A4a and EV, whereas A8, A11 and A11a genotypes displayed a significantly shorter height than EV (Figure 2A). Interestingly, A11 and A1la genotypes gained significantly more height than EV under mild and severe salt stress conditions when data were presented relative to counterpart plants grown under control conditions (Supplementary Figure 6A), indicating an enhanced ability of medium and high miR156 over-expressers to maintain growth under salinity stress.

Number of stems, which impacts biomass yield, was significantly higher in A8, A11, and A11a than in EV under control and mild stress conditions. Furthermore, medium and 

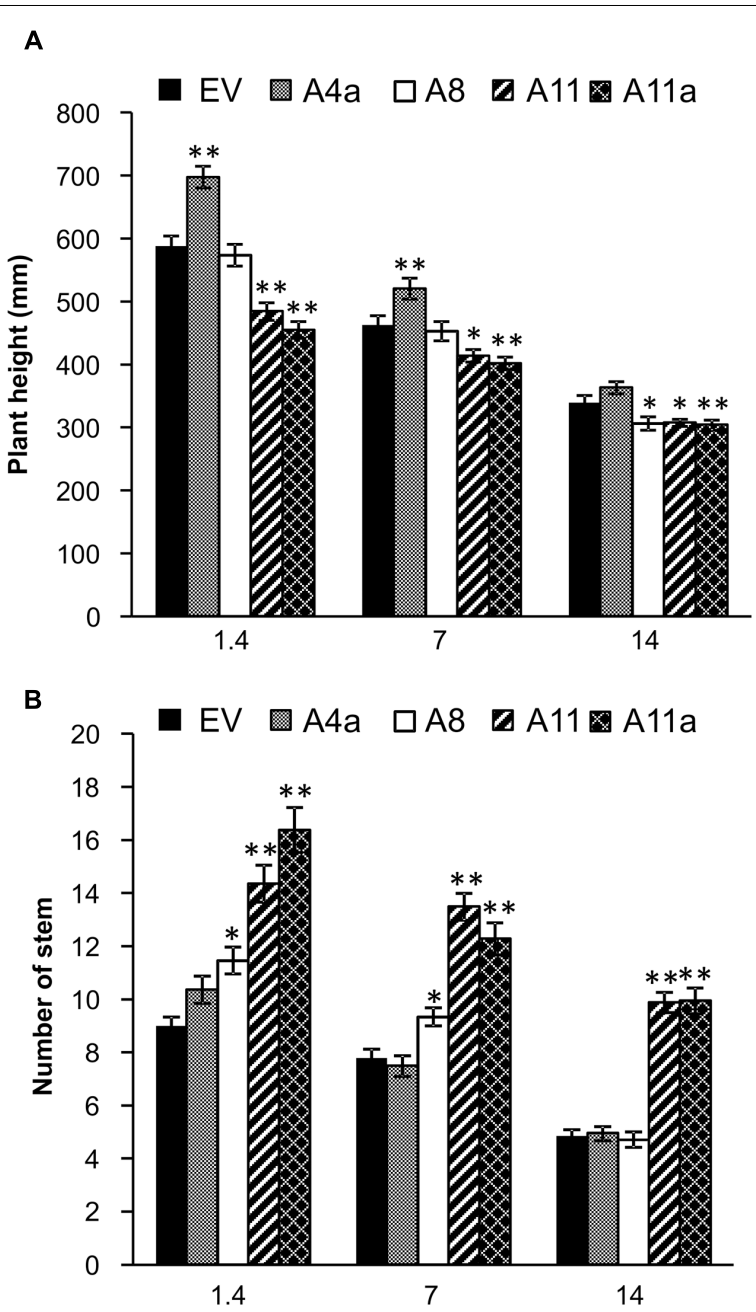

C

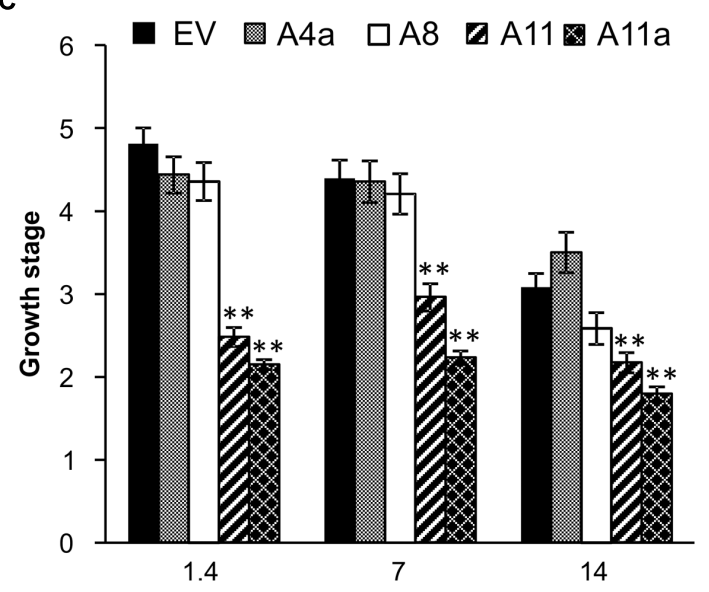

FIGURE 2 | Physiological traits affected by miR156 overexpression under salinity stress. (A) Plant height, (B) stem number, and (C) growth stages. Data are average of four harvests where $n=12$ for each harvest at each stress level (total 48 biological replications for each genotype at each stress level). Single asterisk $\left({ }^{*}\right)$ shows significance at $P<0.05$ and double asterisk (**) indicates $P<0.01$ (ANOVA) between EV and miR156OE genotypes within each stress level (control; $\mathrm{EC}=1.4 \mathrm{dSm}^{-1}$, mild; $\mathrm{EC}=7 \mathrm{dSm}^{-1}$, severe; $\mathrm{EC}=14 \mathrm{dSm}^{-1}$ ). high miR156 over-expressers (A11, A11a) showed a significantly higher number of stems compared to EV under severe salt stress, whereas under similar conditions, low miR156 over-expressers (A4a, A8) showed no differences with EV (Figure 2B). When severe stress results were compared relative to the corresponding controls, A11a and A11 exhibited significantly higher number of stem compared to EV (Supplementary Figure 6B), providing additional evidence that genotypes with higher levels of miR156 possess better ability to withstand salinity and maintain stem growth.

To further investigate the physiological responses, we recorded developmental stages in EV and miR156OE genotypes. At the time of data collection, medium and high miR156 overexpresser (A11, A11a) were between developmental stages 2 and 3, which was significantly lower than EV and low miR156 expressers (A4a, A8) that were already between stages 4 and 5 under control and mild stress conditions (Figure 2C). Similar results were observed under severe stress where A11 and A11a were at or below stage 2 (significantly lower than EV) and low miR156 expressers were at or above stage 3 (Figure 2C). Low miR156 expressers (A4a and A8) exhibited developmental stages that were similar to EV under control, mild and severe stress conditions (Figure 2C). These results indicate that higher expression of miR156 reduces plant height, increases number of branches and delays developmental phases under control and salt stress conditions. To our surprise, medium and high (A11, A11a) miR156 expressers completed developmental stages significantly faster than EV under severe salt stress conditions when results were presented relative to the corresponding unstressed control plants (Supplementary Figure 6C). This suggested a positive role of miR156 in maintenance of alfalfa physiology and development under salinity stress conditions. Taken together our results show that the ability of alfalfa plants to maintain stem growth and biomass under salinity stress improves with increasing miR156 expression.

\section{MicroRNA156 Affects Alfalfa Forage Quality and Antioxidant Levels under Salinity Stress Conditions}

Neutral detergent fiber (NDF) and ADF represent the fiber in plant cell walls and ultimately determine forage quality. Low fiber content indicates higher feed digestibility and nutritional value for animal consumption (Grant et al., 2014). In this study, we observed significantly lower NDF content in three miR156OE genotypes (A8, A11, and A11a) compared to EV under control conditions (Figure 3A). The same three genotypes also showed numerically reduced NDF content during mild and severe salt stress compared to EV but differences were statistically insignificant with EV. NDF content was, however, significantly lower in high miR156 overexpressing genotype (A11) compared to EV during mild stress (Figure 3A). We did not observe significant differences of ADF content between EV and miR156OE genotypes under control or severe salt conditions (Figure 3B). During mild stress, ADF content was significantly reduced in medium and high miR156 over-expressers (A11, A11a) and also in one 

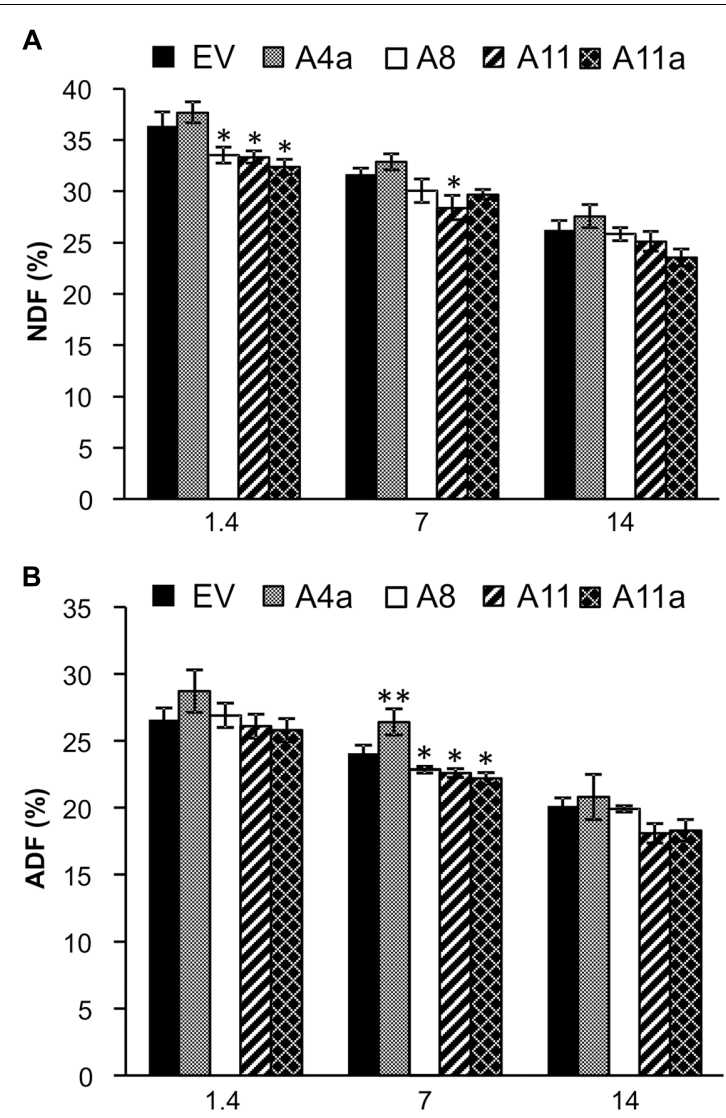

FIGURE 3 | Effects of miR156 on fiber levels under salinity stress. (A) Neutral detergent fiber (NDF) and (B) acid detergent fiber (ADF) content. Data are average of three harvests where $n=3-4$ for each harvest at each stress level (total at least nine biological replications for each genotype at each stress level). Single asterisk $\left(^{*}\right)$ shows significance at $P<0.05$ and double asterisk (**) indicates $P<0.01$ (ANOVA) between EV and miR156OE genotypes within each stress level (control; $\mathrm{EC}=1.4 \mathrm{dSm}^{-1}$, mild; $\mathrm{EC}=7 \mathrm{dSm}^{-1}$, severe; $\mathrm{EC}=14 \mathrm{dSm}^{-1}$ ).

low miR156 over-expresser (A8) compared to EV controls. In contrast, one of the low miR156 over-expressers (A4a) exhibited significantly higher content of ADF compared to EV (Figure 3B).

Nitrogen is an essential component of chlorophyll and amino acids and hence plays a crucial role in photosynthesis and protein synthesis. Overall, we did not observe significant differences in TKN between control and mild stress plants of EV and miR156OE genotypes. During severe salinity stress, however, TKN content was significantly increased in A4a, A11, and A11a compared to unstressed counterparts (Figure 4A). On comparing $\mathrm{EV}$ and miR156OE genotypes, we did not observe differences between EV and three miR156OE genotypes (A8, A11, and A11a) under all conditions. However, a significantly lower level of TKN was observed in A4a compared to EV at control and mild stress (Supplementary Figure 7).

Abiotic stress enhances accumulation of antioxidants in plants to minimize the effect of toxic oxidants produced under stress conditions (Wang et al., 2003). Compared to

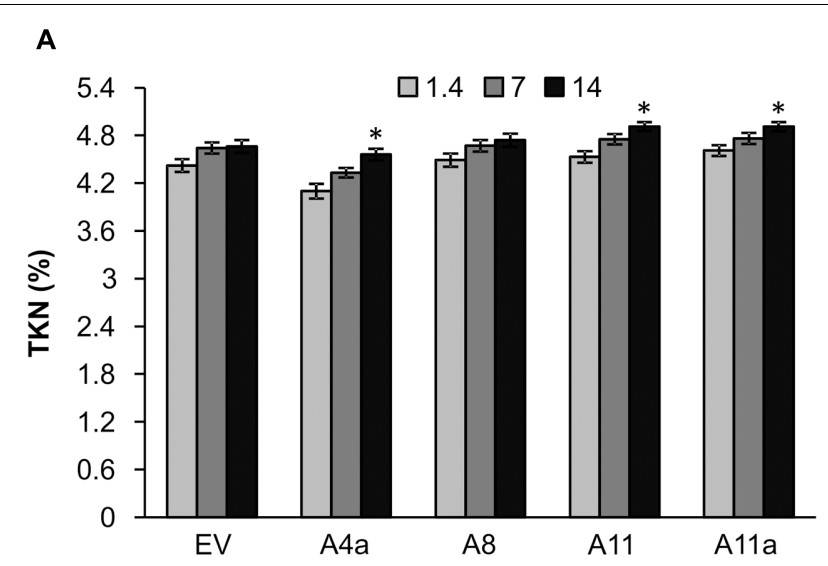

B

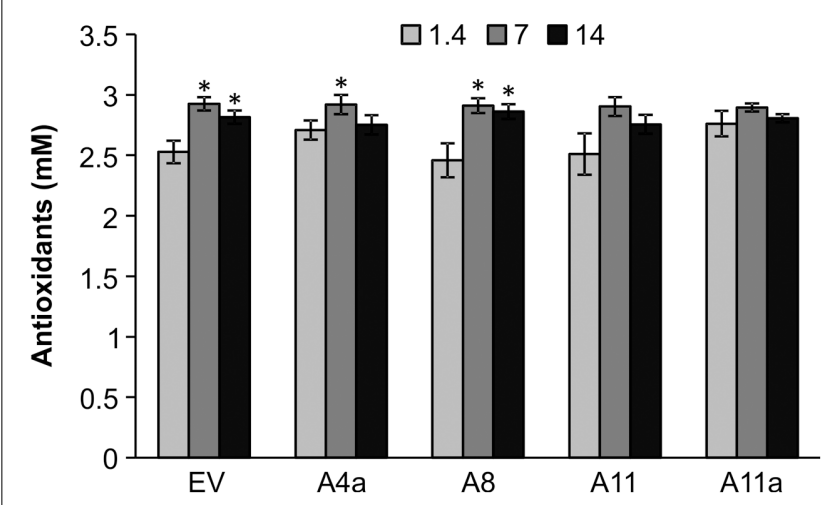

FIGURE 4 | Nitrogen (A) and antioxidant (B) accumulation in EV and miR1560E plants under salinity stress conditions. Data are average of three harvests where $n=4$ for each harvest at each stress level for nitrogen (total 12 biological replications for each genotype at each stress level), and one harvest for antioxidants where $n=4$ for each harvest at each stress level. An asterisk $\left({ }^{*}\right)$ shows significance of mild $\left(E C=7 \mathrm{dSm}^{-1}\right)$ and severe

$\left(E C=14 \mathrm{dSm}^{-1}\right)$ stress from control $\left(E C=1.4 \mathrm{dSm}^{-1}\right)$ for each genotype at $P<0.05$ (ANOVA)

control plants, mild and severe salt stress slightly induced accumulation of antioxidants in EV and a lower miR156 expresser A8 (Figure 4B). On the other hand, another lower miR156 expresser A4a showed increased antioxidant levels only during mild stress compared to corresponding control plants. Furthermore, we did not observe any significant differences in antioxidant accumulation in medium and high miR156 overexpressers (A11, A11a) in response to either mild or severe stress (Figure 4B).

Our results reveal that with increasing miR156 expression, nitrogen content also increases whereas fiber content decreases in alfalfa under same salinity conditions, contributing toward improved alfalfa quality as a forage crop.

\section{MiR156 Modulates Ion Homeostasis under Salinity Stress}

To study alfalfa miR156OE genotypes response to ion uptake under saline conditions, we analyzed sodium $\left(\mathrm{Na}^{+}\right)$, calcium $\left(\mathrm{Ca}^{2+}\right)$, zinc $\left(\mathrm{Zn}^{2+}\right)$, and magnesium $\left(\mathrm{Mg}^{2+}\right)$ ions uptake in 
EV and miR156OE genotypes under control, mild and severe salt stress conditions. Salt stress increased $\mathrm{Na}^{+}$and $\mathrm{Zn}^{2+}$ accumulation in EV and four miR156OE genotypes whereas the same conditions reduced $\mathrm{Ca}^{2+}$ and $\mathrm{Mg}^{2+}$ levels (Supplementary Figure 8). Furthermore, we observed a reduction in $\mathrm{Na}^{+}$ uptake at least in medium and high miR156 expressers (A11a, A11) compared to EV under severe salinity stress. Similarly, we also observed reduced levels of $\mathrm{Zn}^{2+}$ in $\mathrm{A} 11 \mathrm{a}$ during mild stress, and in A8, A1la under severe stress conditions (Table 1). On the other hand, a miR156OE genotype (A4a) exhibited higher levels of $\mathrm{Ca}^{2+}$ than $\mathrm{EV}$ under mild stress. Remaining genotypes showed similar levels of $\mathrm{Ca}^{2+}$ and $\mathrm{Mg}^{2+}$ compared to EV during mild and severe salinity stress (Table 1). These results suggest that alfalfa plants with increased miR156 levels tend to reduce uptake of $\mathrm{Na}^{+}$under severe salt stress conditions.

\section{MiR156 Alters Molecular Responses of Alfalfa under Salinity Stress}

To assess the effect of miR156 on molecular responses of alfalfa to salinity, we analyzed expression of genes belonging to three main categories; (1) SPL family genes - direct target of miR156, (2) non-SPL transcription factors with known function in salt tolerance and, (3) downstream effector genes with known role in mediating salt responses in plants (see Introduction). We tested the expression of genes in the above-mentioned three categories to determine if miR156 affects these important genes and transcription factors under salt stress for regulation of salinity stress responses in alfalfa.

TABLE 1 | Effect of miR156 on ions accumulation in alfalfa.

\begin{tabular}{lcccc}
\hline Genotype & $\mathbf{N a}^{+}$ & $\mathbf{Z n}^{2+}$ & $\mathbf{M g}^{2+}$ & $\mathbf{C a}^{2+}$ \\
\hline Control $(\mathrm{EC}=1.4) \mathrm{ppm}$ & & & \\
EV & $143.1 \pm 16$ & $37.4 \pm 4.5$ & $3286 \pm 101$ & $21132 \pm 493$ \\
A4a & $128.3 \pm 15$ & $30.2 \pm 1.7$ & $2810 \pm 116$ & $19959 \pm 528$ \\
A8 & $135.6 \pm 14$ & $35.8 \pm 3.8$ & $3184 \pm 101$ & $22156 \pm 706$ \\
A11 & $171.6 \pm 20$ & $36.9 \pm 3.7$ & $3244 \pm 125$ & $22982 \pm 572$ \\
A11a & $179.8 \pm 20$ & $42.2 \pm 4.4$ & $3212 \pm 103$ & $23192 \pm 648$ \\
Mild salinity stress $\left(E C=7 \mathrm{dSm}^{-1}\right)-$ relative to control $\left(\mathrm{EC}=1.4 \mathrm{dSm}^{-1}\right)$ \\
EV & $987.6 \pm 153$ & $150.7 \pm 14$ & $74.3 \pm 3.3$ & $72.2 \pm 3.9$ \\
A4a & $817.0 \pm 109$ & $178.4 \pm 29$ & $86.4 \pm 4.3$ & $90.8 \pm 3.7^{*}$ \\
A8 & $1049.6 \pm 149$ & $166.2 \pm 7$ & $76.3 \pm 3.5$ & $81.6 \pm 3.7$ \\
A11 & $881.6 \pm 108$ & $142.3 \pm 14$ & $83.9 \pm 4.2$ & $82.9 \pm 3.2$ \\
A11a & $848.2 \pm 139$ & $119.4 \pm 10^{*}$ & $80.9 \pm 3.9$ & $79.9 \pm 3.5$ \\
Severe salinity stress $\left(\mathrm{EC}=14 \mathrm{dSm}{ }^{-1}\right)-$ relative to control $\left(\mathrm{EC}=1.4 \mathrm{dSm}{ }^{-1}\right)$ \\
EV & $3230.4 \pm 399$ & $208.2 \pm 17$ & $89.3 \pm 4.7$ & $75.4 \pm 5.8$ \\
A4a & $2749.2 \pm 273$ & $205.9 \pm 13$ & $96.1 \pm 4.7$ & $89.4 \pm 6.9$ \\
A8 & $3873.9 \pm 472$ & $166.3 \pm 7^{*}$ & $89.9 \pm 4.1$ & $82.4 \pm 6.7$ \\
A11 & $2219.4 \pm 273^{*}$ & $202.3 \pm 20$ & $97.3 \pm 4.4$ & $83.2 \pm 6.6$ \\
A11a & $2269.5 \pm 332^{*}$ & $169.8 \pm 8^{*}$ & $92.0 \pm 4.3$ & $79.9 \pm 5.7$ \\
\hline
\end{tabular}

lons levels in EV and miR156OE genotypes in response to salinity stress. Values of $\mathrm{Na}^{+}, \mathrm{Ca}^{2+}, \mathrm{Mg}^{2+}$, and $\mathrm{Zn}^{2+}$ at mild $\left(E C=7 \mathrm{dSm}^{-1}\right)$ and severe $\left(E C=14 \mathrm{dSm}^{-1}\right)$ stress are percent of corresponding controls $\left(E C=1.4 \mathrm{dSm}^{-1}\right)$, which is arbitrarily set to 100. Single asterisk (*) shows significance at $P<0.05$ (ANOVA) between EV and miR156OE genotypes of each ion at each stress level.

\section{Expression Analysis of miR156-Target SPL Transcription Factors}

To assess miR156-regulated molecular responses, we assessed the expression pattern of three miR156-target $S P L$ genes (SPL6, SPL12, and SPL13) (Aung et al., 2015a) in our miR156 over-expressing alfalfa plants. Overall, we observed a consistent pattern of SPL gene downregulation in medium and high miR156 expressers under non-stressed and stressed environments compared to low expressers or EV. In leaves, overall expression of SPL6, SPL12, and SPL13 was increased in EV under mild and severe stress conditions whereas expression of these genes was suppressed in all miR156OE genotypes compared to unstressed control (Figure 5A). Expression of SPL6 was significantly reduced in A11 during mild stress and in all miR156OE genotypes under severe stress conditions (Figure 5A). Similarly, expression of SPL12 was significantly reduced in miR156OE genotypes (except A11) and under control and severe stress conditions (except A4a). Mild stress, however, did not cause a significant difference in SPL12 expression (Figure 5A). Furthermore, SPL13 expression was also significantly reduced in A8 and A11a under mild stress and in A8, A11, and A11a at severe stress compared to EV (Figure 5A).

In roots, we observed a significant downregulation of SPL6 under severe salt stress with three miR156OE genotypes (A8, A11, and A11a) showing reduced expression. More pronounced results were observed in SPL13 expression, which was significantly downregulated in all miR156OE genotypes compared to EV under control and severe stress conditions (Figure 5B). However, we did not detect significant changes of SPL12 expression in root (data not shown). These results suggest that miR156 targets SPL family more efficiently under salt stress conditions.

\section{Expression Analysis of Abiotic Stress Responsive Non-SPL Transcription Factors}

In leaves, transcription factor ZFP showed no difference in expression between EV and miR156OE genotypes under control conditions (Figure 6A). During mild stress, expression of ZFP1 was significantly higher in three miR156OE genotypes (A8, A11, and A11a) and, in addition, a strong and significant induction was observed in all miR156OE genotypes compared to EV during severe stress (Figure 6A). The ethylene response factor $(E R F)$ also showed no expression differences between EV and miR156OE genotypes (except A4a) under control conditions. Upon exposing plants to mild salinity stress, $E R F$ expression was similar between miR156OE genotypes (except A11a) and EV. More prominent expression differences were observed under severe stress conditions when miR156OE genotypes showed significant upregulation of ERF compared to EV (Figure 6A). A similar expression pattern was observed also for AP2 domain transcription factor (AP2), which was significantly induced in miR156OE genotypes under severe salt stress (Figure 6A).

In roots, medium and high miR156 expressers (A11, A11a) showed significant upregulation of ZFP1 compared to EV under control conditions (Figure 6B). Under mild stress, all miR156OE genotypes showed expression of ZFP1 that was similar to EV. More pronounced results were observed during 


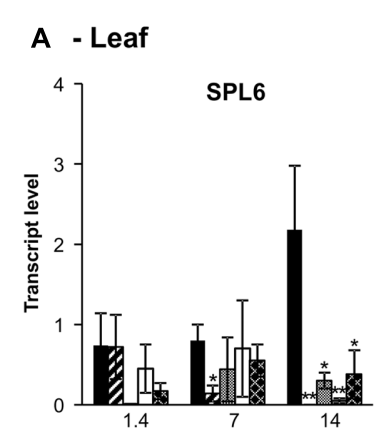

EV $\square$ A11 $\square$ A4a $\square$ A8 $\mathrm{A} 11 \mathrm{a}$
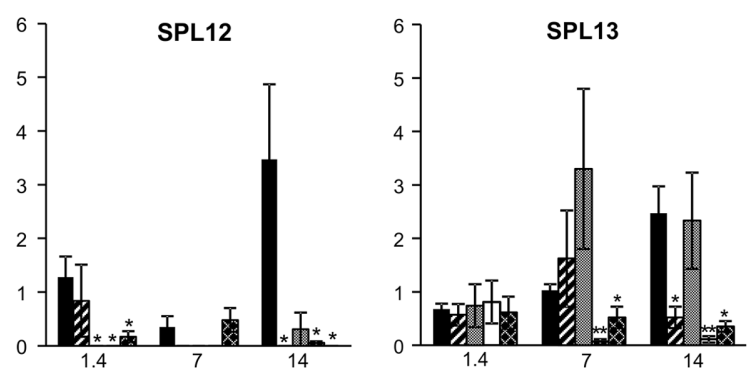

\section{B - Root}
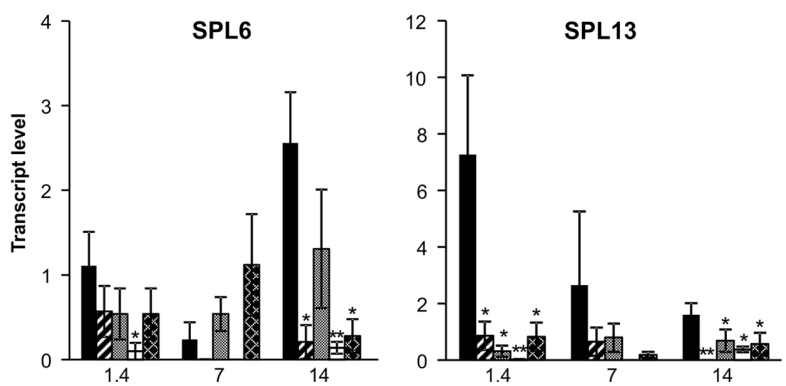

FIGURE 5 | Relative transcript levels of miR156-target SPL genes in leaves (A) and roots (B). Data are average of 3-4 biological replicates for each genotype at each stress level. Single asterisk (*) shows significance at $P<0.05$ and double asterisk (**) indicates $P<0.01$ ( $t$-test) between EV and miR156OE genotypes within each stress level (control; $\mathrm{EC}=1.4 \mathrm{dSm}^{-1}$, mild; $\mathrm{EC}=7 \mathrm{dSm}^{-1}$, severe; $\mathrm{EC}=14 \mathrm{dSm}^{-1}$ ).

A - Leaf

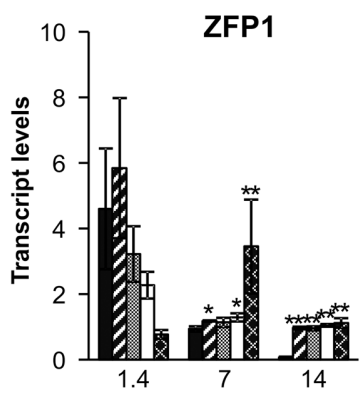

B - Root

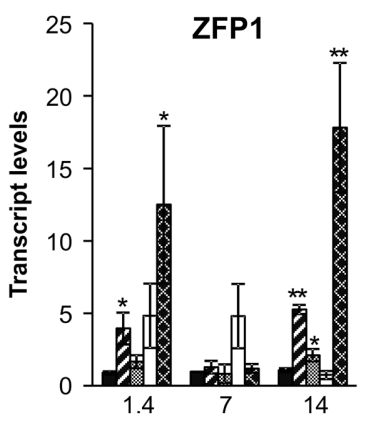

$E V A 11 \square A 4 a \square A 8 \otimes A 11 a$
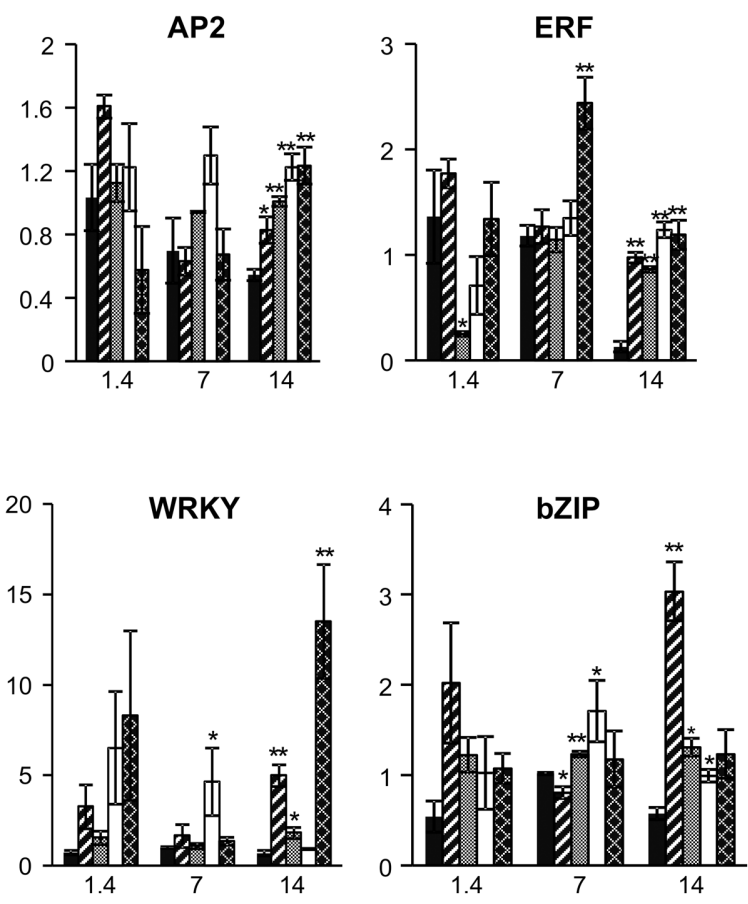

FIGURE 6 | Relative transcript levels of abiotic stress responsive transcription factors in leaves (A) and roots (B). Data are average of 3-4 biological replicates for each genotype at each stress level. Single asterisk $\left(^{*}\right)$ shows significance at $P<0.05$ and double asterisk $(* *)$ indicates $P<0.01(t$-test) between EV and miR156OE genotypes within each stress level (control; $\mathrm{EC}=1.4 \mathrm{dSm}^{-1}$, mild; $\mathrm{EC}=7 \mathrm{dSm}^{-1}, \mathrm{severe}^{\mathrm{E}} \mathrm{EC}=14 \mathrm{dSm}{ }^{-1}$ ). 
severe stress when three miR156OE genotypes (A4a, A11, and A11a) showed significantly higher expression, and A8 showed similar expression of ZFP1 compared to EV (Figure 6B). WRKY and $b Z I P$ transcription factors exhibited similar expression to miR156OE genotypes and EV under control conditions (Figure 6B). Expression of WRKY was also similar between EV and miR156OE (except A8) at mild stress, whereas under severe stress, WRKY was significantly upregulated in three miR156OE (A4a, A11, and A11a) genotypes. Under mild stress, expression of root $b Z I P$ was significantly induced in two low miR156 expressers (A8, A4a), significantly lower in a higher expresser (A11), but no different in a medium miR156 expresser (A11a) compared to EV. All miR156OE genotypes showed upregulation of $b Z I P$ at severe stress with A4a, A8, and A11 showing significant differences compared with EV (Figure 6B). Expression differences of AP2 and ERF in roots, and WRKY and bZIP in leaves were not significant between EV and miR156OE genotypes under control and stress conditions (data not shown). Expression patterns of transcription factors that differ between leaves and roots suggested that miR156 affects transcriptional activities in a tissue-specific manner.

\section{Expression Analysis of Downstream Candidate Salt Responsive Genes}

We further analyzed expression of candidate genes involved in salt stress tolerance such as vacuolar $\mathrm{Na}^{+} / \mathrm{H}^{+}$antiporter $(\mathrm{NHX})$, plasma membrane $\mathrm{H}^{+}$-ATPase, cation $/ \mathrm{H}^{+}$exchanger 3; a putative homolog of Arabidopsis salt overly sensitive 1 (SOS1), low temperature and salt responsive family protein 2 (RCI2), Vacuolar $H^{+}$pumping ATPase (VATP), Glycine rich protein (GRP) and a cytokinin receptor homolog (HK1). VATP, GRP, NHX1, RCI2, $\mathrm{H}^{+}$-ATPase and SOS1 are salt-induced genes, and their over-expression enhanced salinity stress tolerance in plants (Coba de la Pena et al., 2008; Bao et al., 2009; Yang et al., 2009; Leidi et al., 2010; Long et al., 2013). In leaves, transcript levels of VATP were significantly increased only in low miR156 expressers, whereas expression levels of GRP and $H K 1$ were insignificant in miR156OE genotypes compared to EV under control conditions (Figure 7A). Mild stress, however, induced expression of VATP in low miR156 expressers (A4a and A8) while reducing VATP transcription in a medium miR156 expresser (A11a) compared to EV. Under mild stress conditions, A11 showed expression of VATP that was similar with EV. Furthermore, severe salt stress induced expression of VATP in leaves of all miR156OE genotypes, with A8, A4a, and A11a being significantly higher than EV (Figure 7A). GRP expression was significantly increased in miR156OE genotypes (except A4a) under mild stress, while all miR156OE genotypes exhibited significant upregulation of GRP under severe stress conditions (Figure 7A). In addition, all miR156OE genotypes showed significant upregulation of $H K 1$ under mild (except A11a) and severe salt stress compared to EV (Figure 7A). Similarly, $H^{+}$-ATPase and SOS1 showed similar expression trends in leaves where low miR156 expressers (A8, A4a) exhibited higher expression during mild stress, and A11 and A11a showed higher expression under severe salt stress compared to $\mathrm{EV}$ (Figure 7A).
In roots, expression of GRP, NHX1, and RCI2 was significantly or insignificantly higher in miR156OE genotypes compared to $\mathrm{EV}$ control. We also did not observe a significant difference in expression of VATP between EV and miR156OE genotypes under control and mild stress conditions (except in A8 under mild stress). However, during severe stress VATP expression was significantly induced in A11a but reduced in A8, while remaining similar in A4a and A11 compared to EV (Figure 7B). Compared to $\mathrm{EV}$, all miR156OE genotypes showed higher expression of GRP under severe stress conditions, while A11 showed higher expression only under non-saline conditions and A4a and A8 under mild stress (Figure 7B). The miR156OE genotypes showed higher expression of $N H X 1$ even under non-saline conditions, with A8 and A11 having significantly higher expression than in EV (Figure 7B). During mild stress, only A8 showed significantly higher expression of NHX1 whereas under severe stress, A8, A11, and A11a showed significantly higher expression compared to EV (Figure 7B). Similarly, medium and high expressers (A11, A11a), showed higher expression of RCI2 compared to EV under control conditions. Under mild stress, only A11a exhibited upregulation of RCI2 compared to EV whereas under severe stress conditions, three miR156OE genotypes (A8, A11, and A11a) exhibited upregulation of this genes compared to EV (Figure 7B). We did not observe significant differences in expression of $N H X 1$ and RCI2 in leaves, and HK1, $H^{+}$-ATPase, and SOS1 in roots of miR156OE genotypes and EV (data not shown).

These results suggest that miR156 affects expression of candidate salt responsive genes in a tissue-specific manner under stress conditions. Importantly, we observed more pronounced and consistent results in medium and high miR156 expressers (A11, A11a) under severe salinity stress (EC 14).

\section{DISCUSSION}

Salinity is a serious threat to growth and productivity of alfalfa and other crops around the world. In addition, climate change may intensify abiotic stress conditions including salinity in alfalfa growing regions, particularly in the North American prairies. Salt tolerant genotypes have different strategies to cope with stress conditions such as slowing down growth, synthesizing defense compounds and antioxidants, altering gene expression and maintaining ion homeostasis. In this study, we dissected the role of miR156 in salinity tolerance of alfalfa. Our results suggest that transgenic alfalfa plants with medium to high miR156 expression (A11a, A11) exhibit consistent and robust responses under severe salinity stress (EC $14 \mathrm{dSm}^{-1}$ ) compared to the genotypes with low miR156 expression levels (A4a, A8), and under medium stress (EC $7 \mathrm{dSm}^{-1}$ ) or control (EC $1.4 \mathrm{dSm}^{-1}$ ) conditions.

\section{Improved Biomass and Forage Quality under Salinity Stress}

Alfalfa biomass is an important trait for forage and biofuel industries. In our study, miR156 overexpressing plants exhibited an increase in shoot and root biomass under control conditions as previously reported (Aung et al., 2015a). Normally, 


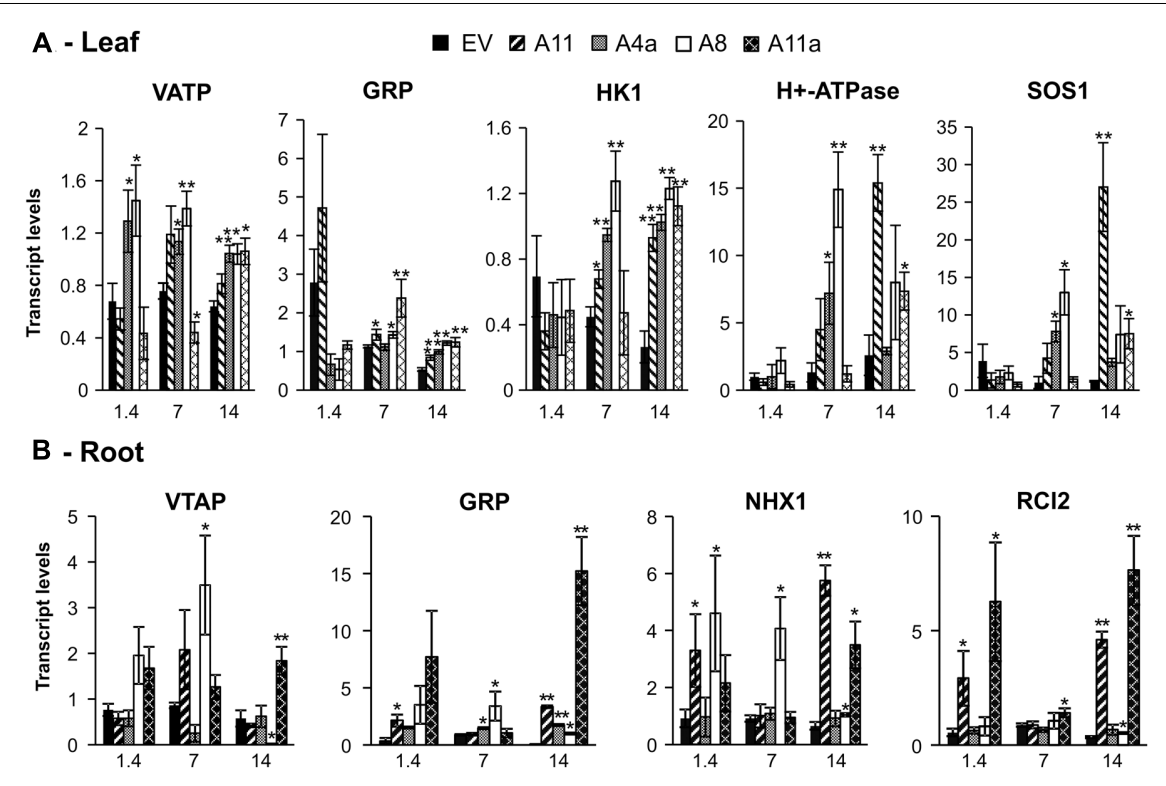

FIGURE 7 | Relative transcript levels of salt stress responsive genes in leaves (A) and roots (B). Data are average of 3-4 biological replicates for each genotype at each stress level. Single asterisk $(*)$ shows significance at $P<0.05$ and double asterisk $(* *)$ indicates $P<0.01(t$-test) between EV and miR156OE genotypes within each stress level (control; $\mathrm{EC}=1.4 \mathrm{dSm}^{-1}$, mild; $\mathrm{EC}=7 \mathrm{dSm}^{-1}$, severe; $\mathrm{EC}=14 \mathrm{dSm}^{-1}$ ).

salinity reduces plant biomass accumulation (Li et al., 2010) but, interestingly, we recorded a less reduction in biomass accumulation in miR156OE genotypes relative to $\mathrm{EV}$ under severe stress condition. In absolute term, an increased branching (shoot number) and slower developmental stage completion by miR156OE genotypes compared to EV may have contributed to the accumulation of higher biomass. Surprisingly, miR156OE genotypes were quick in completing developmental stages, and also exhibited increased plant growth (height, stem, and developmental stages) in relation to their corresponding controls, when compared with EV under stress conditions, indicating a stress avoidance mechanism in transgenic alfalfa plants under salinity stress. Previously, an increased shoot growth was observed in tomato and rice under salt stress (Zhu et al., 1998; Mayak et al., 2004).

Total Kjehldahl nitrogen (TKN), NDF, and ADF contribute to forage quality and digestibility. Protein increases forage quality, and reduction in nitrogen content leads to reduced crude protein content, which ultimately reduces forage quality (Owensby et al., 1996). NDF consists of cellulose, hemicellulose and lignin whereas ADF contains mainly cellulose and lignin but lacks hemicellulose (Van Soest, 1994). Furthermore, NDF and ADF are components of fiber that can reduce digestibility, palatability, and intake of forages leading to degradation of forage quality (Van Soest, 1994). Our study shows a significant increase of TKN in response to severe salt stress in three miR156OE genotypes but not in EV plants. Moreover, we recorded a reduction of NDF and $\mathrm{ADF}$ in miR156OE genotypes compared to EV under control and mild salt stress conditions, respectively. An increased TKN and decreased NDF and ADF content in miR156OE genotypes indicates that miR156 also contributes to alfalfa forage quality improvement under normal and saline conditions. A study has shown an improved forage quality of bermudagrass and wheatgrass under salinity stress (Robinson et al., 2004). Similarly, in another study miR156 overexpression led to enhanced forage quality in switchgrass (Fu et al., 2012).

\section{Molecular Responses and Ion Homeostasis in Transgenic Plants under Salinity Stress}

Higher levels of $\mathrm{Na}^{+}$ions can cause ion toxicity resulting in reduced plant growth and performance. Several membrane transporters particularly $\mathrm{Na}^{+}$and $\mathrm{K}^{+}$transporters play a crucial role in salinity tolerance in plants (Schroeder et al., 2013). Most studies have been conducted in Arabidopsis where cytokinin mediates expression of AtHKT1 in a negative manner via type $B$ response regulators ARR1 and ARR12, thereby indicating that cytokinin levels are reduced in response to salinity stress, resulting in induction of AtHKT1 expression (Mason et al., 2010), which supports our $H K 1$ expression results.

Previously, studies have identified a group of $H K T$ transporters that regulate $\mathrm{Na}^{+} / \mathrm{K}^{+}$co-transport (Rubio et al., 1995). Subsequent studies have suggested that AtHKT1-mediated $\mathrm{Na}^{+}$removal from the xylem stimulates $\mathrm{K}^{+}$loading into xylem, resulting in a high $\mathrm{K}^{+} / \mathrm{Na}^{+}$ratio in leaves that also alleviates $\mathrm{Na}^{+}$stress (Ren et al., 2005; Sunarpi et al., 2005). There is an additional study showing that HKTs play a crucial role in determining a high $\mathrm{K}^{+} / \mathrm{Na}^{+}$ratio in plants. For example, a TaHKT1 gene contributed to $\mathrm{Na}^{+}$removal from xylem in the leaf sheath of durum wheat to protect leaf blades from $\mathrm{Na}^{+}$ over accumulation and toxicity (Huang et al., 2006). Mutating Arabidopsis HKT gene in (AtHKT1) caused $\mathrm{Na}^{+}$hypersensitivity, as well as enhanced accumulation of $\mathrm{Na}^{+}$upon salinity stress in 
Arabidopsis leaves (Mäser et al., 2002; Berthomieu et al., 2003; Horie et al., 2006). Subsequent studies further demonstrated the role of $A t H K T 1$, and a rice ortholog OsHKT1, in removing $\mathrm{Na}^{+}$ and protecting leaves from $\mathrm{Na}^{+}$toxicity (Ren et al., 2005; Sunarpi et al., 2005; Davenport et al., 2007). Another study conducted on root stellar cells in Athkt1 mutant plants provided additional evidence that AtHKT1 mediates passive $\mathrm{Na}^{+}$channel-like transport (Xue et al., 2011).

In our study, salt stress induced $\mathrm{Na}^{+}$accumulation in $\mathrm{EV}$ and all miR156OE genotypes, but this accumulation was reduced in moderate and high miR156 expressers (A11, A11a) compared to $\mathrm{EV}$ under severe stress conditions. Reduced accumulation of $\mathrm{Na}^{+}$ in A11 and A11a could be due to induced expression of HK1 in these genotypes under severe stress since HKT transporters play key role in $\mathrm{Na}^{+}$efflux from the xylem (Sunarpi et al., 2005). Furthermore, tonoplast and plasma membrane localized NHXs antiporters are essential for maintaining low $\mathrm{Na}^{+}$in the cytoplasm and $\mathrm{Na}^{+}$detoxification via sequestering within the vacuole (Deinlein et al., 2014). Over-expression of NHX led to salinity tolerance in Arabidopsis (Apse et al., 1999). A recent transcriptome study revealed that alfalfa transporter genes HKT1 and anion exchanger maintained high transcript levels in salt tolerant alfalfa genotypes (Gruber et al., 2016). $\mathrm{Na}^{+}$influx can raise sodium concentration inside the cytosol activating $\mathrm{K}^{+}$efflux and disturbing $\mathrm{K}^{+} / \mathrm{Na}^{+}$ratio (Sun et al., 2009; Britto et al., 2010). The high-affinity $\mathrm{K}^{+}$transporter $(H K T)$ family transports $\mathrm{Na}^{+}$ and $\mathrm{K}^{+}$(Benito et al., 2014). Our results showed reduced $\mathrm{Na}^{+}$ concentration in medium and high miR156 expressors (A11, A11a) under severe stress, which may have increased $\mathrm{K}^{+}$influx. This is also supported by induced expression of $H K 1$ in leaves of miR156OE genotypes. Overexpression of Arabidopsis $\mathrm{H}^{+}$ATPase and SOS1 enhances salt tolerance in plants (Bao et al., 2009; Yang et al., 2009). In our study, an enhanced expression of NHX1 in root and HK1, $H^{+}$-ATPase and SOS1 in leaves of medium and higher miR156 expressers under severe saline conditions may have contributed to the removal of $\mathrm{Na}^{+}$and a reduction of its toxicity in these genotypes.

Salinity stress induces antioxidant accumulation in plants to counter the damage caused by oxidants under stress conditions (Bose et al., 2014). In our study, we did not observe a slight induction of antioxidants in medium and higher expressers of miR156 (A11, A11a) under mild or severe stress. This may indicate that these genotypes may have low internal stress level compared to EV and low miR156 expressers (A4a, A8) that accumulated significantly higher levels of antioxidants in response to mild and severe stress.

Given that SPL transcription factors (SPL6, SPL12, and SPL13) are targeted by miR156 (Aung et al., 2015a), it is important to analyze their expression patterns to better understand the mechanism of salt tolerance regulated by miR156. Previously, there was one study that revealed that rSPL9 (expressing miR156insensitive SPL9) and rSPL10 (expressing miR156-insensitive SPL10) plants exhibited hypersensitivity to drought and salt stress (Cui et al., 2014). Their results indicate that SPLs could potentially be negative regulators of stress response. Similarly, genes encoding non-SPL transcription factors such as ZFP1, $A P 2, E R F, W R K Y$, and $b Z I P$ and other downstream effector

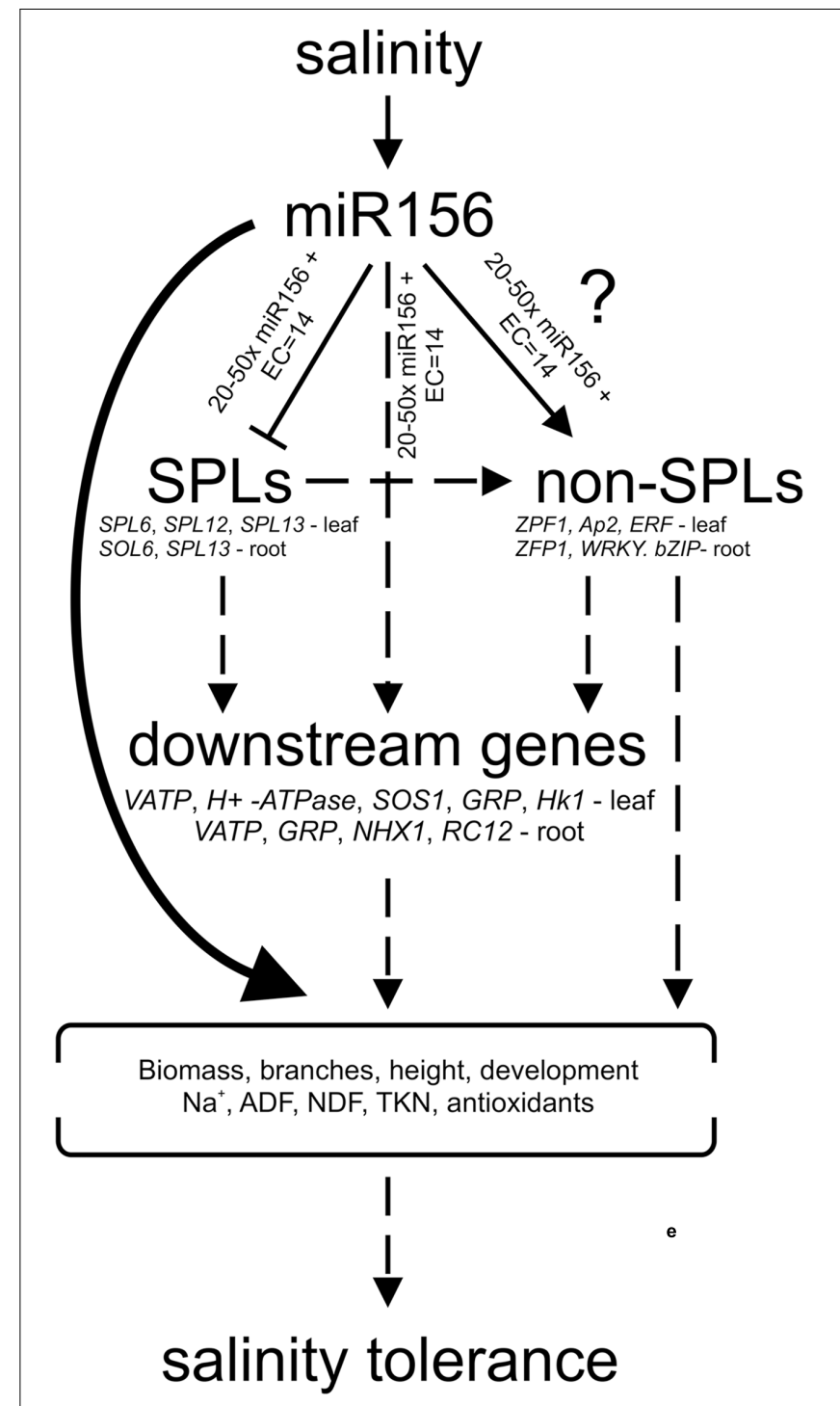

FIGURE 8 | A model showing pathways for salinity tolerance in alfalfa. Solid lines or arrows indicate a pathway supported by experimental evidence or reports from literature. Dotted lines or arrows show a suggested pathway.

genes play vital role in salt tolerance in plants (Singh et al., 2002; Ciftci-Yilmaz and Mittler, 2008; Jiang and Deyholos, 2009; Pandey and Somssich, 2009; Rushton et al., 2010; Mizoi et al., 2012; Shi et al., 2014; Hu et al., 2016), and testing expression of these genes could also be helpful in expanding list of direct or indirect targets of miR156 particularly under salt stress. This information could be helpful in drawing a pathway that miR156 uses to regulate salinity stress responses in alfalfa (Figure 8).

Several studies have established that miR156 modulates abiotic stress responses in various plant species (Wang M. et al., 2013; Cui et al., 2014; Kohli et al., 2014; Stief et al., 2014; Xie et al., 2014; Wang and Wang, 2015). MiR156 controls plant responses through targeting SPL family transcription factors (Aung et al., 2015a), which in turn may alter expression of downstream genes. 
We observed downregulation of SPL genes in leaves and roots under stress conditions indicating that miR156 expedites the cleavage of SPLs to modulate stress responses in alfalfa. SPL genes respond to abiotic stress and stimulate the synthesis of secondary metabolites (Wang M. et al., 2013; Yu et al., 2015) showing that they may directly or indirectly be involved in stress tolerance.

Under salt stress conditions, several genes and transcription factors including WRKY, ZFP, $b Z I P$, and ERF/AP2 are upregulated to help plants adapt to saline conditions (Golldack et al., 2011; Deinlein et al., 2014). In our study, however, not all the tested genes and transcription factors were upregulated in response to salt stress. An enhanced expression of WRKY and ZFP1 in leaf and root, ERF and AP2 in leaf, and bZIP in root of miR156OE genotypes under salt stress indicates that transcription activities were increased in miR156OE genotypes. We hypothesize that as transcription activators, SPLs may have an inverse relationship with other stress responsive transcription factors (Gou et al., 2011), and a reduced expression of SPLs may have led to enhanced transcriptional activities of WRKY, ZFP, bZIP, and $E R F / A P 2$ transcription factors in leaves and roots of stressed alfalfa plants.

Overexpression of downstream salt responsive genes such as NHX1, VATP, GRP, HK1 RCI2, $H^{+}$-ATPase, and SOS1 improve salt stress tolerance in plants (Coba de la Pena et al., 2008; Silva and Geros, 2009; Leidi et al., 2010; Long et al., 2013, 2015). In our study, upregulation of these genes in leaf and root of miR156OE genotypes under salt stress conditions may have contributed to salt stress tolerance of transgenic alfalfa. This also provides further support to our hypothesis that high transcription activities in miR156OE plants led to altered expression of downstream genes resulting in an adaptive response of alfalfa plants to salt stress.

Overall, three common tendencies can be found in our data; (1) tissue-specific -in case of SPL12, ERF, AP2, GRP, HK1, (show expression differences only in leaf) and WRKY, bZIP, NHX1, $R C I 2$ (show differences only in root), (2) severe stress-specific show consistent downregulation of SPLs, and upregulation of non-SPLs transcription factor as well as downstream effector genes under severe stress conditions across leaf and root, and (3) miR156 level-specific - show consistently significant results in medium and high miR156 expresssors (A11, A11a). This supports our hypothesis that a relationship exists between miR156 levels, SPLs, non-SPL transcription factors and downstream genes.

Taken together, we report that miR156 positively regulates salinity response in alfalfa partially by altering expression of important transcription factors and downstream genes. Thus, a trend seems to exist where increased expression of miR156 exhibits a salt tolerant phenotype during severe stress. We noted that gene expression in plants is differently regulated and depends on the intensity of stress and the tolerance or sensitivity of the genotypes. Our results are in line with other published studies. For example, a study by (Rodrigues et al., 2009) showed an insignificant expression of several genes at mild water stress in sugarcane cultivars, but their expression was significantly increased under severe stress. In support of genotypic differences, (El Maarouf et al., 1999) observed that a susceptible cowpea genotype showed enhanced expression of Phospholipase D under drought stress conditions whereas a tolerant genotype showed low expression of this gene throughout the experiment. These studies support our results of variable expression in different genotypes at different stress levels.

Several studies in other plant species have revealed that miR156 levels do not only change in response to salt stress but also under various other stresses such as heat, drought, cold, UV-B radiation, and hypoxia (Zhou et al., 2008; Jia et al., 2009; Moldovan et al., 2010; Cui et al., 2014; Stief et al., 2014). However, we cannot rule out the possibility that salt stress response is in part regulated by additional salt-responsive genes and transcription factors not identified in this study, which may directly or indirectly be regulated by miR156. Whereas this study reveals a role for miR156 in salt stress response, further studies involving next generation sequencing, and functional characterization of target SPL genes and downstream SPLregulated genes would be needed to fully understand how miR156 affects salt tolerance. Our recent study has shown SPL13 as a negative regulator of drought responses in alfalfa (Arshad et al., 2017), and a similar work under salt stress would provide a better understanding of how the miR156SPL gene regulatory network affects salt tolerance. The detailed analysis of the regulation of miR156, and other salt-responsive genes and transcription factors remains an important area of research, as it will be interesting to see whether miR156 along with identified genes and transcription factors also play a role in improving tolerance to other stresses in various plant species.

\section{CONCLUSION}

We propose that high miR156 levels (20-50 times) result in a robust and consistent response to salinity stress in alfalfa. Similar miR156 levels improve growth, biomass and forage quality of alfalfa during salinity stress. Elevated levels of miR156 reduce the uptake of toxic ions and increase beneficial ions, a condition which may contribute to salinity tolerance. In addition, we hypothesize that miR156 directly or indirectly targets transcription factors including SPLs, which in turn may regulate downstream genes in a stress-specific manner leading to salinity stress tolerance in alfalfa. These transcription factors and downstream affected genes could be suitable targets for alfalfa breeding programs.

\section{AUTHOR CONTRIBUTIONS}

MA conducted experiments, collected, analyzed and interpreted data, as well as drafted manuscript. MG conducted experiments, collected data, and edited manuscript. KW conducted experiments and collected data. AH secured funding, oversaw the project and edited manuscript. All authors critically reviewed and approved the final manuscript. 


\section{FUNDING}

Funding for this project was through a grant from Agriculture and Agri-Food Canada (AAFC) to AH.

\section{ACKNOWLEDGMENTS}

We thank Ms. Lisa Amyot (AAFC-London) and Ms. Min $\mathrm{Yu}$ (AAFC-Saskatoon) for making rooted cuttings and

\section{REFERENCES}

Ahmed, I. M., Dai, H., Zheng, W., Cao, F., Zhang, G., Sun, D., et al. (2013). Genotypic differences in physiological characteristics in the tolerance to drought and salinity combined stress between Tibetan wild and cultivated barley. Plant. Physiol. Biochem. 63, 49-60. doi: 10.1016/j.plaphy.2012.11.004

Allen, E., Xie, Z., Gustafson, A. M., and Carrington, J. C. (2005). microRNAdirected phasing during trans-acting siRNA biogenesis in plants. Cell 121, 207-221. doi: 10.1016/j.cell.2005.04.004

Apse, M. P., Aharon, G. S., Snedden, W. A., and Blumwald, E. (1999). Salt tolerance conferred by overexpression of a vacuolar $\mathrm{Na}+/ \mathrm{H}+$ antiport in Arabidopsis. Science 285, 1256-1258. doi: 10.1126/science.285.5431.1256

Arshad, M., Feyissa, B. A., Amyot, L., Aung, B., and Hannoufa, A. (2017). MicroRNA156 improves drought stress tolerance in alfalfa (Medicago sativa) by silencing SPL13. Plant. Sci. doi: 10.1016/j.plantsci.2017.01.018

Aung, B., Gruber, M. Y., Amyot, L., Omari, K., Bertrand, A., and Hannoufa, A. (2015a). MicroRNA156 as a promising tool for alfalfa improvement. Plant Biotechnol. J. 13, 779-790. doi: 10.1111/pbi.12308

Aung, B., Gruber, M. Y., and Hannoufa, A. (2015b). The MicroRNA156 system: a tool in plant biotechnology. Biocatal. Agric. Biotechnol. 4, 432-442. doi: $10.1016 /$ j.bcab.2015.08.002

Bao, A. K., Wang, S. M., Wu, G. Q., Xi, J. J., Zhang, J. L., and Wang, C. M. (2009). Overexpression of the Arabidopsis $\mathrm{H}+$-PPase enhanced resistance to salt and drought stress in transgenic alfalfa (Medicago sativa L.). Plant Sci. 176, 232-240. doi: 10.1016/j.plantsci.2008.10.009

Benito, B., Haro, R., Amtmann, A., Cuin, T. A., and Dreyer, I. (2014). The twins $\mathrm{K}+$ and $\mathrm{Na}+$ in plants. J. Plant Physiol. 171, 723-731. doi: 10.1016/j.jplph.2013. 10.014

Berthomieu, P., Conéjéro, G., Nublat, A., Brackenbury, W. J., Lambert, C., Savio, C., et al. (2003). Functional analysis of AtHKT1 in Arabidopsis shows that $\mathrm{Na}+$ recirculation by the phloem is crucial for salt tolerance. $E M B O J .22$, 2004-2014. doi: 10.1093/emboj/cdg207

Bielewicz, D., Kalak, M., Kalyna, M., Windels, D., Barta, A., Vazquez, F., et al. (2013). Introns of plant pri-miRNAs enhance miRNA biogenesis. EMBO Rep. 14, 622-628. doi: 10.1038/embor.2013.62

Bose, J., Rodrigo-Moreno, A., and Shabala, S. (2014). ROS homeostasis in halophytes in the context of salinity stress tolerance. J. Exp. Bot. 65, 1241-1257. doi: $10.1093 / \mathrm{jxb} / \mathrm{ert} 430$

Britto, D. T., Ebrahimi-Ardebili, S., Hamam, A. M., Coskun, D., and Kronzucker, H. J. (2010). $42 \mathrm{~K}$ analysis of sodium-induced potassium efflux in barley: mechanism and relevance to salt tolerance. New. Phytol. 186, 373-384. doi: $10.1111 / j .1469-8137.2009 .03169 . x$

Brodersen, P., Sakvarelidze-Achard, L., Bruun-Rasmussen, M., Dunoyer, P., Yamamoto, Y. Y., Sieburth, L., et al. (2008). Widespread translational inhibition by plant miRNAs and siRNAs. Science 320, 1185-1190. doi: 10.1126/science. 1159151

Chen, T., Yang, Q., Gruber, M., Kang, J., Sun, Y., Ding, W., et al. (2012a). Expression of an alfalfa (Medicago sativa L.) ethylene response factor gene MsERF8 in tobacco plants enhances resistance to salinity. Mol. Biol. Rep. 39, 6067-6075. doi: 10.1007/s11033-011-1421-y

Chen, T., Yang, Q., Zhang, X., Ding, W., and Gruber, M. (2012b). An alfalfa (Medicago sativa L.) ethylene response factor gene, MsERF11, enhances salt tolerance in transgenic Arabidopsis. Plant Cell Rep. 31, 1737-1746. doi: 10.1007/ s00299-012-1287-z maintaining the plant material. We also thank Alex Molnar (AAFC-London) for his help in arranging figures for this manuscript.

\section{SUPPLEMENTARY MATERIAL}

The Supplementary Material for this article can be found online at: http://journal.frontiersin.org/article/10.3389/fpls.2017.00356/ full\#supplementary-material

Ciftci-Yilmaz, S., and Mittler, R. (2008). The zinc finger network of plants. Cell. Mol. Life Sci. 65, 1150-1160. doi: 10.1007/s00018-007-7473-4

Coba de la Pena, T., Carcamo, C. B., Almonacid, L., Zaballos, A., Lucas, M. M., Balomenos, D., et al. (2008). A salt stress-responsive cytokinin receptor homologue isolated from Medicago sativa nodules. Planta 227, 769-779. doi: 10.1007/s00425-007-0655-3

Couzigou, J. M., and Combier, J. P. (2016). Plant microRNAs: key regulators of root architecture and biotic interactions. New Phytol. 212, 22-35. doi: 10.1111/nph. 14058

Cui, L. G., Shan, J. X., Shi, M., Gao, J. P., and Lin, H. X. (2014). The miR156-SPL9DFR pathway coordinates the relationship between development and abiotic stress tolerance in plants. Plant. J. 80, 1108-1117. doi: 10.1111/tpj.12712

Davenport, R. J., Muñoz-Mayor, A., Jha, D., Essah, P. A., Rus, A., and Tester, M. (2007). The $\mathrm{Na}+$ transporter AtHKT1;1 controls retrieval of $\mathrm{Na}+$ from the xylem in Arabidopsis. Plant Cell Environ. 30, 497-507. doi: 10.1111/j.1365-3040. 2007.01637.x

Deinlein, U., Stephan, A. B., Horie, T., Luo, W., Xu, G., and Schroeder, J. I. (2014). Plant salt-tolerance mechanisms. Trends Plant Sci. 19, 371-379. doi: 10.1016/j.tplants.2014.02.001

El Maarouf, H., Zuily-Fodil, Y., Gareil, M., D'arcy-Lameta, A., and PhamThi, A. T. (1999). Enzymatic activity and gene expression under water stress of phospholipase D in two cultivars of Vigna unguiculata L.Walp. differing in drought tolerance. Plant Mol. Biol. 39, 1257-1265. doi: 10.1023/A: 1006165919928

Ferreira, G., and Mertens, D. R. (2007). Measuring detergent fibre and insoluble protein in corn silage using crucibles or filter bags. Anim. Feed Sci. Technol. 133, 335-340. doi: 10.1016/j.anifeedsci.2006.04.010

Fick, G. W., and Mueller, S. C. (1989). Alfalfa: quality, maturity, and mean stage of development. Inf. Bull. 217, 1-16.

Fu, C., Sunkar, R., Zhou, C., Shen, H., Zhang, J. Y., Matts, J., et al. (2012). Overexpression of miR156 in switchgrass (Panicum virgatum L.) results in various morphological alterations and leads to improved biomass production. Plant Biotechnol. J. 10, 443-452. doi: 10.1111/j.1467-7652.2011.00677.x

Gao, R., Austin, R. S., Amyot, L., and Hannoufa, A. (2016). Comparative transcriptome investigation of global gene expression changes caused by miR156 overexpression in Medicago sativa. BMC Genomics 17:658. doi: 10.1186/s12864-016-3014-6

Goering, H. K., and Van Soest, P. J. (1970). Forage Fiber Analyses (Apparatus, Reagents, Prcedures, and Some Applications). Washington, DC: Agricultural Research Service.

Golldack, D., Luking, I., and Yang, O. (2011). Plant tolerance to drought and salinity: stress regulating transcription factors and their functional significance in the cellular transcriptional network. Plant Cell Rep. 30, 1383-1391. doi: 10.1007/s00299-011-1068-0

Gou, J. Y., Felippes, F. F., Liu, C. J., Weigel, D., and Wang, J. W. (2011). Negative regulation of anthocyanin biosynthesis in Arabidopsis by a miR156-targeted SPL transcription factor. Plant Cell 23, 1512-1522. doi: 10.1105/tpc.111. 084525

Graham, P. H., and Vance, C. P. (2003). Legumes: importance and constraints to greater use. Plant Physiol. 131, 872-877. doi: 10.1104/pp.017004

Grant, K., Kreyling, J., Dienstbach, L. F. H., Beierkuhnlein, C., and Jentsch, A. (2014). Water stress due to increased intra-annual precipitation variability reduced forage yield but raised forage quality of a temperate grassland. Agric. Ecosyst. Environ. 186, 11-22. doi: 10.1016/j.agee.2014.01.013 
Gruber, M., Xia, J., Yu, M., Steppuhn, H., Wall, K., Messer, D., et al. (2016). Transcript analysis in two alfalfa salt tolerance selected breeding populations relative to a nontolerant population. Genome 60, 104-127. doi: 10.1139/gen2016-0111

Hobert, O. (2004). Common logic of transcription factor and microRNA action. Trends Biochem. Sci. 29, 462-468. doi: 10.1016/j.tibs.2004.07.001

Hobert, O. (2008). Gene regulation by transcription factors and MicroRNAs. Science 319, 1785-1786. doi: 10.1126/science.1151651

Horie, T., Horie, R., Chan, W. Y., Leung, H. Y., and Schroeder, J. I. (2006). Calcium regulation of sodium hypersensitivities of sos 3 and athkt1 mutants. Plant Cell Physiol. 47, 622-633. doi: 10.1093/pcp/pcj029

Hu, W., Yang, H., Yan, Y., Wei, Y., Tie, W., Ding, Z., et al. (2016). Genome-wide characterization and analysis of bZIP transcription factor gene family related to abiotic stress in cassava. Sci. Rep. 6:22783. doi: 10.1038/srep22783

Huang, S., Spielmeyer, W., Lagudah, E. S., James, R. A., Platten, J. D., Dennis, E. S., et al. (2006). A sodium transporter (HKT7) is a candidate for Nax1, a gene for salt tolerance in durum wheat. Plant Physiol. 142, 1718-1727. doi: 10.1104/pp.106.088864

Jia, X., Ren, L., Chen, Q. J., Li, R., and Tang, G. (2009). UV-B-responsive microRNAs in Populus tremula. J. Plant Physiol. 166, 2046-2057. doi: 10.1016/ j.jplph.2009.06.011

Jiang, Y., and Deyholos, M. K. (2009). Functional characterization of Arabidopsis $\mathrm{NaCl}$-inducible WRKY25 and WRKY33 transcription factors in abiotic stresses. Plant Mol. Biol. 69, 91-105. doi: 10.1007/s11103-008-9408-3

Jones, J. B. (1991). "Plant tissue analysis in micronutrients," in Micronutrients in Agriculture, eds J. J. Mortvedt, F. R. Cox, L. M. Shuman, and R. M. Welch (Madison, WI: Social Science Society of America), 477-521.

Jones-Rhoades, M. W., and Bartel, D. P. (2004). Computational identification of plant microRNAs and their targets, including a stress-induced miRNA. Mol. Cell 14, 787-799. doi: 10.1016/j.molcel.2004.05.027

Kim, Y. J., Zheng, B., Yu, Y., Won, S. Y., Mo, B., and Chen, X. (2011). The role of mediator in small and long noncoding RNA production in Arabidopsis thaliana. EMBO J. 30, 814-822. doi: 10.1038/emboj.2011.3

Kohli, D., Joshi, G., Deokar, A. A., Bhardwaj, A. R., Agarwal, M., KatiyarAgarwal, S., et al. (2014). Identification and characterization of wilt and salt stress-responsive MicroRNAs in chickpea through high-throughput sequencing. PLoS ONE 9:e108851. doi: 10.1371/journal.pone.0108851

Lee, S. C., Choi, H. W., Hwang, I. S., Choi, D. S., and Hwang, B. K. (2006). Functional roles of the pepper pathogen-induced bZIP transcription factor, CAbZIP1, in enhanced resistance to pathogen infection and environmental stresses. Planta 224, 1209-1225. doi: 10.1007/s00425-006-0302-4

Lee, S. J., Kang, J. Y., Park, H. J., Kim, M. D., Bae, M. S., Choi, H. I., et al. (2010). DREB2C interacts with ABF2, a bZIP protein regulating abscisic acid-responsive gene expression, and its overexpression affects abscisic acid sensitivity. Plant Physiol. 153, 716-727. doi: 10.1104/pp.110.154617

Leidi, E. O., Barragan, V., Rubio, L., El-Hamdaoui, A., Ruiz, M. T., Cubero, B., et al. (2010). The AtNHX1 exchanger mediates potassium compartmentation in vacuoles of transgenic tomato. Plant. J. 61, 495-506. doi: 10.1111/j.1365-313X. 2009.04073.x

Li, R., Shi, F., Fukuda, K., and Yang, Y. (2010). Effects of salt and alkali stresses on germination, growth, photosynthesis and ion accumulation in alfalfa (Medicago sativa L.). Soil Sci. Plant Nutr. 56, 725-733. doi: 10.1111/j.1747-0765.2010. 00506.x

Li, Y., Sun, Y., Yang, Q., Fang, F., Kang, J., and Zhang, T. (2013). Isolation and characterization of a gene from Medicago sativa L., encoding a bZIP transcription factor. Mol. Biol. Rep. 40, 1227-1239. doi: 10.1007/s11033-0122165-z

Long, R., Yang, Q., Kang, J., Chao, Y., Wang, P., Wu, M., et al. (2012). Molecular cloning and characterization of a novel stress responsive gene in alfalfa. Biol. Plant. 56, 43-49. doi: 10.1007/s10535-012-0014-5

Long, R., Yang, Q., Kang, J., Zhang, T., Wang, H., Li, M., et al. (2013). Overexpression of a novel salt stress-induced glycine-rich protein gene from alfalfa causes salt and ABA sensitivity in Arabidopsis. Plant Cell Rep. 32, 1289-1298. doi: 10.1007/s00299-013-1443-0

Long, R., Zhang, F., Li, Z., Li, M., Cong, L., Kang, J., et al. (2015). Isolation and functional characterization of salt-stress induced RCI2-like genes from Medicago sativa and Medicago truncatula. J. Plant Res. 128, 697-707. doi: 10. 1007/s10265-015-0715-x
Mangeon, A., Junqueira, R. M., and Sachetto-Martins, G. (2010). Functional diversity of the plant glycine-rich proteins superfamily. Plant Signal. Behav. 5, 99-104. doi: 10.4161/psb.5.2.10336

Mäser, P., Eckelman, B., Vaidyanathan, R., Horie, T., Fairbairn, D. J., Kubo, M., et al. (2002). Altered shoot/root Na+ distribution and bifurcating salt sensitivity in Arabidopsis by genetic disruption of the $\mathrm{Na}+$ transporter AtHKT1. FEBS Lett. 531, 157-161. doi: 10.1016/S0014-5793(02)03488-9

Mason, M. G., Jha, D., Salt, D. E., Tester, M., Hill, K., Kieber, J. J., et al. (2010). Type-B response regulators ARR1 and ARR12 regulate expression of AtHKT1;1 and accumulation of sodium in Arabidopsis shoots. Plant J. 64, 753-763. doi: 10.1111/j.1365-313X.2010.04366.x

Mayak, S., Tirosh, T., and Glick, B. R. (2004). Plant growth-promoting bacteria confer resistance in tomato plants to salt stress. Plant Physiol. Biochem. 42, 565-572. doi: 10.1016/j.plaphy.2004.05.009

Mizoi, J., Shinozaki, K., and Yamaguchi-Shinozaki, K. (2012). AP2/ERF family transcription factors in plant abiotic stress responses. Biochim. Biophys. Acta 1819, 86-96. doi: 10.1016/j.bbagrm.2011.08.004

Moldovan, D., Spriggs, A., Yang, J., Pogson, B. J., Dennis, E. S., and Wilson, I. W. (2010). Hypoxia-responsive microRNAs and trans-acting small interfering RNAs in Arabidopsis. J. Exp. Bot. 61, 165-177. doi: 10.1093/jxb/erp296

Munns, R. (2002). Comparative physiology of salt and water stress. Plant Cell Environ. 25, 239-250. doi: 10.1046/j.0016-8025.2001.00808.x

Munns, R., and Tester, M. (2008). Mechanisms of salinity tolerance. Annu. Rev. Plant. Biol. 59, 651-681. doi: 10.1146/annurev.arplant.59.032607.092911

Noel, R., and Hambleton, L. (1976). Collaborative study of a semiautomated method for the determination of crude protein in animal feeds. J. Assoc. Off. Anal. Chem. 59, 134-140.

Owensby, C. E., Cochran, R. C., and Auen, L. M. (1996). "Effects of elevated carbon dioxide on forage quality for ruminants," in Carbon Dioxide, Populations, and Communities, eds C. Koerner and F. Bazzaz (Cambridge, MA: Academic Press), 363-371. doi: 10.1016/b978-012420870-4/50056-6

Pandey, S. P., and Somssich, I. E. (2009). The role of WRKY transcription factors in plant immunity. Plant Physiol. 150, 1648-1655. doi: 10.1104/pp.109.138990

Parida, A. K., and Das, A. B. (2005). Salt tolerance and salinity effects on plants: a review. Ecotoxicol. Environ. Saf. 60, 324-349. doi: 10.1016/j.ecoenv.2004.06.010

Parvaiz, A., and Satyawati, S. (2008). Salt stress and phyto-biochemical responses of plants-A review. Plant Soil Environ. 54, 89-99.

Paul, D., and Lade, H. (2014). Plant-growth-promoting rhizobacteria to improve crop growth in saline soils: a review. Agron. Sustain. Dev. 34, 737-752. doi: 10.1007/s13593-014-0233-6

Reis, R. S., Eamens, A. L., and Waterhouse, P. M. (2015). Missing pieces in the puzzle of plant MicroRNAs. Trends Plant Sci. 20, 721-728. doi: 10.1016/j. tplants.2015.08.003

Ren, Z. H., Gao, J. P., Li, L. G., Cai, X. L., Huang, W., Chao, D. Y., et al. (2005). A rice quantitative trait locus for salt tolerance encodes a sodium transporter. Nat. Genet. 37, 1141-1146. doi: 10.1038/ng1643

Rhoades, M. W., Reinhart, B. J., Lim, L. P., Burge, C. B., Bartel, B., and Bartel, D. P. (2002). Prediction of plant microRNA targets. Cell 110, 513-520. doi: 10.1016/S0092-8674(02)00863-2

Ringli, C., Keller, B., and Ryser, U. (2001). Glycine-rich proteins as structural components of plant cell walls. Cell Mol. Life Sci. 58, 1430-1441. doi: 10.1007/ PL00000786

Robinson, P. H., Grattan, S. R., Getachew, G., Grieve, C. M., Poss, J. A., Suarez, D. L., et al. (2004). Biomass accumulation and potential nutritive value of some forages irrigated with saline-sodic drainage water. Anim. Feed. Sci. Technol. 111, 175-189. doi: 10.1016/S0377-8401(03)00213-X

Rodrigues, F. A., De Laia, M. L., and Zingaretti, S. M. (2009). Analysis of gene expression profiles under water stress in tolerant and sensitive sugarcane plants. Plant Sci. 176, 286-302. doi: 10.1016/j.plantsci.2008.11.007

Rogers, K., and Chen, X. (2013). Biogenesis, turnover, and mode of action of plant microRNAs. Plant Cell 25, 2383-2399. doi: 10.1105/tpc.113.113159

Rubio, F., Gassmann, W., and Schroeder, J. I. (1995). Sodium-driven potassium uptake by the plant potassium transporter HKT1 and mutations conferring salt tolerance. Science 270, 1660-1663. doi: 10.1126/science.270.5242. 1660

Rushton, P. J., Somssich, I. E., Ringler, P., and Shen, Q. J. (2010). WRKY transcription factors. Trends Plant Sci. 15, 247-258. doi: 10.1016/j.tplants.2010. 02.006 
Schmittgen, T. D., and Livak, K. J. (2008). Analyzing real-time PCR data by the comparative CT method. Nat. Protoc. 3, 1101-1108. doi: 10.1038/nprot.2008.73

Schroeder, J. I., Delhaize, E., Frommer, W. B., Guerinot, M. L., Harrison, M. J., Herrera-Estrella, L., et al. (2013). Using membrane transporters to improve crops for sustainable food production. Nature 497, 60-66. doi: 10.1038/ nature11909

Shi, H., Wang, X., Ye, T., Chen, F., Deng, J., Yang, P., et al. (2014). The Cysteine2/Histidine2-type transcription factor zinc finger of Arabidopsis thaliana 6 modulates biotic and abiotic stress responses by activating salicylic acid-related genes and C-Repeat-binding factor genes in Arabidopsis. Plant Physiol. 165, 1367-1379. doi: 10.1104/pp.114.242404

Silva, P., and Geros, H. (2009). Regulation by salt of vacuolar $\mathrm{H}^{+}$-ATPase and $\mathrm{H}^{+}$-pyrophosphatase activities and $\mathrm{Na}^{+} / \mathrm{H}^{+}$exchange. Plant Signal. Behav. 4, 718-726. doi: 10.4161/psb.4.8.9236

Singh, K., Foley, R. C., and Onate-Sanchez, L. (2002). Transcription factors in plant defense and stress responses. Curr. Opin. Plant. Biol. 5, 430-436. doi: 10.1016/S1369-5266(02)00289-3

Steppuhn, H., Acharya, S. N., Iwaasa, A. D., Gruber, M., and Miller, D. R. (2012). Inherent responses to root-zone salinity in nine alfalfa populations. Can. J. Plant Sci. 92, 235-248. doi: 10.4141/cjps2011-174

Stief, A., Altmann, S., Hoffmann, K., Pant, B. D., Scheible, W. R., and Bäurle, I. (2014). Arabidopsis miR156 regulates tolerance to recurring environmental stress through SPL transcription factors. Plant Cell 26, 1792-1807. doi: 10.1105/ tpc.114.123851

Sun, J., Chen, S., Dai, S., Wang, R., Li, N., Shen, X., et al. (2009). NaCl-induced alternations of cellular and tissue ion fluxes in roots of salt-resistant and saltsensitive poplar species. Plant Physiol. 149, 1141-1153. doi: 10.1104/pp.108. 129494

Sunarpi, Horie, T., Motoda, J., Kubo, M., Yang, H., Yoda, K., et al. (2005). Enhanced salt tolerance mediated by AtHKT1 transporter-induced $\mathrm{Na}+$ unloading from xylem vessels to xylem parenchyma cells. Plant J. 44, 928-938. doi: 10.1111/j. 1365-313X.2005.02595.x

Tang, L., Cai, H., Ji, W., Luo, X., Wang, Z., Wu, J., et al. (2013). Overexpression of GsZFP1 enhances salt and drought tolerance in transgenic alfalfa (Medicago sativa L.). Plant Physiol. Biochem. 71, 22-30. doi: 10.1016/j.plaphy.2013. 06.024

Tang, L., Cai, H., Zhai, H., Luo, X., Wang, Z., Cui, L., et al. (2014). Overexpression of Glycine soja WRKY20 enhances both drought and salt tolerance in transgenic alfalfa (Medicago sativa L.). Plant Cell Tissue Organ. Cult. 118, 77-86. doi: 10.1016/j.plaphy.2013.06.024

Tuoxiong, C., Shuihong, C., and Xinshi, L. (2010). Research on photosynthetic characteristics of fall dormant alfalfa under salt stress. J. Northeast. Agric. Univ. 11,024 .

Van Soest, P. J. (1994). Nutritional Ecology of the Ruminant. Ithaca, NY: Cornell University Press.

Varley, J. A. (1966). Automatic methods for the determination of nitrogen, phosphorus and potassium in plant material. Analyst 91, 119-126. doi: 10.1039/ an9669100119

Wang, B.-P., Dong, X.-Y., and Dong, K.-H. (2013). Effects of saline-alkali stress on the physiological characteristics of alfalfa seedlings. Acta Agrestia Sin. $6,017$.

Wang, M., Wang, Q., and Zhang, B. (2013). Response of miRNAs and their targets to salt and drought stresses in cotton (Gossypium hirsutum L.). Gene 530, 26-32. doi: $10.1016 /$ j.gene.2013.08.009

Wang, H., and Wang, H. (2015). The miR156/SPL module, a regulatory hub and versatile toolbox, gears up crops for enhanced agronomic traits. Mol. Plant 8 , 677-688. doi: 10.1016/j.molp.2015.01.008
Wang, W., Vinocur, B., and Altman, A. (2003). Plant responses to drought, salinity and extreme temperatures: towards genetic engineering for stress tolerance. Planta 218, 1-14. doi: 10.1007/s00425-003-1105-5

Wang, W. B., Kim, Y. H., Lee, H. S., Kim, K. Y., Deng, X. P., and Kwak, S. S. (2009). Analysis of antioxidant enzyme activity during germination of alfalfa under salt and drought stresses. Plant Physiol. Biochem. 47, 570-577. doi: 10.1016/j.plaphy. 2009.02.009

Wang, Y., Wang, Z., Amyot, L., Tian, L., Xu, Z., Gruber, M. Y., et al. (2015). Ectopic expression of miR156 represses nodulation and causes morphological and developmental changes in Lotus japonicus. Mol. Genet. Genomics 290, 471-484. doi: 10.1007/s00438-014-0931-4

Wezel, A., Casagrande, M., Celette, F., Vian, J. F., Ferrer, A., and Peigné, J. (2014). Agroecological practices for sustainable agriculture. A review. Agron. Sustain. Dev. 34, 1-20. doi: 10.1007/s13593-013-0180-7

Xie, F., Stewart, C. N., Taki, F. A., He, Q., Liu, H., and Zhang, B. (2014). Highthroughput deep sequencing shows that microRNAs play important roles in switchgrass responses to drought and salinity stress. Plant Biotechnol. J. 12, 354-366. doi: 10.1111/pbi.12142

Xue, S., Yao, X., Luo, W., Jha, D., Tester, M., Horie, T., et al. (2011). AtHKT1;1 mediates nernstian sodium channel transport properties in Arabidopsis root stelar cells. PLoS ONE 6:e24725. doi: 10.1371/journal.pone.0024725

Yang, Q., Chen, Z. Z., Zhou, X. F., Yin, H. B., Li, X., Xin, X. F., et al. (2009). Overexpression of SOS (salt overly sensitive) genes increases salt tolerance in transgenic Arabidopsis. Mol. Plant 2, 22-31. doi: 10.1093/mp/ssn058

Yu, Z. X., Wang, L. J., Zhao, B., Shan, C. M., Zhang, Y. H., Chen, D. F., et al. (2015). Progressive regulation of sesquiterpene biosynthesis in Arabidopsis and Patchouli (Pogostemon cablin) by the miR156-targeted SPL transcription factors. Mol. Plant 8, 98-110. doi: 10.1016/j.molp.2014.11.002

Zhang, B., and Wang, Q. (2015). MicroRNA-based biotechnology for plant improvement. J. Cell. Physiol. 230, 1-15. doi: 10.1002/jcp.24685

Zhang, Y. M., Zhang, H. M., Liu, Z. H., Li, H. C., Guo, X. L., and Li, G. L. (2015). The wheat NHX antiporter gene TaNHX2 confers salt tolerance in transgenic alfalfa by increasing the retention capacity of intracellular potassium. Plant Mol. Biol. 87, 317-327. doi: 10.1007/s11103-014-0278-6

Zhou, X., Wang, G., Sutoh, K., Zhu, J. K., and Zhang, W. (2008). Identification of cold-inducible microRNAs in plants by transcriptome analysis. Biochim. Biophys. Acta 1779, 780-788. doi: 10.1016/j.bbagrm.2008.04.005

Zhu, B., Su, J., Chang, M., Verma, D. P. S., Fan, Y. L., and Wu, R. (1998). Overexpression of a $\Delta 1$-pyrroline-5-carboxylate synthetase gene and analysis of tolerance to water- and salt-stress in transgenic rice. Plant Sci. 139, 41-48. doi: 10.1016/S0168-9452(98)00175-7

Zhu, J. K. (2002). Salt and drought stress signal transduction in plants. Annu. Rev. Plant Biol. 53, 247-273. doi: 10.1146/annurev.arplant.53.091401.143329

Zou, M., Guan, Y., Ren, H., Zhang, F., and Chen, F. (2008). A bZIP transcription factor, OsABI5, is involved in rice fertility and stress tolerance. Plant Mol. Biol. 66, 675-683. doi: 10.1007/s11103-008-9298-4

Conflict of Interest Statement: The authors declare that the research was conducted in the absence of any commercial or financial relationships that could be construed as a potential conflict of interest.

Copyright $(2017$ Arshad, Gruber, Wall and Hannoufa. This is an open-access article distributed under the terms of the Creative Commons Attribution License (CC BY). The use, distribution or reproduction in other forums is permitted, provided the original author(s) or licensor are credited and that the original publication in this journal is cited, in accordance with accepted academic practice. No use, distribution or reproduction is permitted which does not comply with these terms. 